\title{
Alimentos, TECNOLOGÍAS VEGETALES Y \\ PALEOAMBIENTE EN LAS ALDEAS FORMATIVAS DE LA PAMPA DEL TAMARUGAL, TARAPACÁ \\ (ca. 900 AC-800 DC)
}

\author{
Magdalena García, ${ }^{1}$ Alejandra Vidal, ${ }^{2}$ Valentina Mandakovic, ${ }^{3}$ Antonio Maldonado, ${ }^{4}$ \\ María Paz Peña ${ }^{5}$ Eliana Belmonte ${ }^{6}$
}

\section{* Introducción}

Resumen

Este trabajo pretende introducir a los usos e imaginarios relacionados con las plantas en las aldeas formativas de la Pampa del Tamarugal, Tarapacá (Chile). Se estudiaron los restos vegetales recuperados de las excavaciones de los sitios Pircas y Caserones, en la quebrada de Tarapacá, así como de Guatacondo 1 y Ramaditas, en la de Guatacondo. Estas aldeas poseen contextos domésticos, ceremoniales, mortuorios y de almacenaje, asociados a alimentos silvestres y cultivados, así como un amplio universo artefactual, principalmente en madera, que incluye materias primas, instrumentos y desechos de talla. Se concluye que, si bien las cuatro aldeas comparten aspectos significativos como su orientación agrícola y forestal, las ocupaciones de ambas cuencas expresan situaciones disímiles que permiten cuestionar la noción evolucionista que se ha tenido del período Formativo como una sucesión unilineal de etapas de progreso.

Palabras claves: aldeas - Prosopis - alimentos - tecnologías vegetales período Formativo - Tarapacá.

\begin{abstract}
The aim of this work is to introduce to the uses and imaginaries related to the plants in the formative villages of Pampa del Tamarugal, Tarapacá region (Chile). To accomplish this, we studied the plant remains recovered from excavations in the sites of Pircas and Caserones in

the ravine of Tarapacá, as well as Guatacondo 1 and Ramaditas in the Guatacondo ravine. These villages have domestic, ceremonial, mortuary and storage contexts, from which were recovered wild and cultivated food and a wide artefactual universe, mainly in wood, including raw materials, artifacts and wastes. We conclude that while the four villages share significant aspects like their agriculture and forestry orientation, their occupations are dissimilar, which permits us to question the evolutionary notion that understands the Formative period as a unilinear succession of stages of progress.
\end{abstract}

Key words: villages - Prosopis - food - plant technologies - Formative period - Tarapacá.

Recibido: marzo 2012. Aceptado: junio 2013.
Los estudios arqueológicos recientes en la Pampa del Tamarugal, específicamente en las aldeas Pircas, Caserones, Guatacondo 1 y Ramaditas, reafirman la idea de que el período Formativo (ca. $900 \mathrm{AC}-800 \mathrm{DC}$ ) no se manifiesta de manera hegemónica ni revolucionaria, sino que constituye la continuación de un largo proceso de experimentación iniciado desde el Arcaico (ca.6000-1000 AC), en el cual las distintas sociedades de la región no fueron alcanzando etapas sucesivas de desarrollo de manera unilineal, sino que cada cuenca tuvo su ritmo propio así como desiguales logros y tragedias (Uribe 2008; Uribe y Adán 2009). En este sentido, los contextos arqueológicos evidencian una heterogeneidad significativa de prácticas, tales como caza, pesca, recolección, silvicultura y agricultura, entre otros. El costo de la resistencia o la transformación hacia nuevos modos de vida complejos implicó la acumulación de evidentes tensiones, las cuales se manifiestan, por ejemplo, en la experimentación de formas de asentamiento disímiles - con casos en que el despliegue arquitectónico no tiene ningún correlato con lo efímero de la ocupación- y en la fuerte ritualidad vinculada al espacio habitacional. Por todo lo anterior, creemos necesario abandonar las explicaciones funcionalistas y evolucionistas basadas en generalizaciones y dicotomías tales como recolección/agricultura, silvestre/doméstico, asentamiento disperso/nucleado, secular/sagrado, ya que no dan cuenta de la complejidad de estas aldeas ni de lo que narran las materialidades (Méndez-Quirós 2012).

\footnotetext{
1 Programa de Doctorado en Arqueología Universidad Católica del Norte, Instituto de Investigaciones Arqueológicas y Museo. Gustavo Le Paige 380, San Pedro de Atacama, CP. 1410000, CHILE. Email: manegarciab@yahoo.com

2 Facultad de Estudios del Patrimonio Cultural, Universidad Internacional SEK. Campus Parque Arrieta, Av. José Arrieta 10.000, Peñalolén, CHILE.Email: alejandra.vidal@zonavirtual.sek.cl
} 
Desde el Arcaico, las comunidades de la costa incluyeron prácticas de complementariedad con el interior, distantes entre 40 y $60 \mathrm{~km}$, con lo cual el litoral se fue articulando con la Pampa del Tamarugal, dominada por los bosques de Prosopis y los valles endorreicos que descienden desde la Puna. Los testigos arqueológicos de esta interacción son elocuentes en los basurales domésticos y en los múltiples senderos que comunican ambos espacios a través de las serranías costeras (True et al. 1970; Núñez 1985; Briones et al. 2005; Núñez y Santoro 2011). De este modo, esta temprana articulación de las tierras bajas constituye un rasgo de continuidad entre el Arcaico y el Formativo y, con ello, un elemento central para comprender el proceso aldeano, de modo similar como ha sido planteado para las llamadas adaptaciones agromarítimas de los valles del extremo norte de Chile y sur de Perú (Moseley 1975; Santoro 1980; Muñoz 1982; Núñez y Santoro 2011). En particular, desde los vegetales, esta situación se expresa en la permanencia de ciertas manufacturas como agujas de cactus así como esteras y cordelerías elaboradas en totora, junquillo y algodón, presentes en los contextos arqueológicos de ambos espacios (Núñez y Moragas 1977; Muñoz et al. 1991; Standen 2003).

En los 70, Núñez señalaba que "para el norte de Chile la situación es compleja, por la falta de documentación arqueobotánica" (1974: 122). Si bien en los últimos años esta tendencia se ha ido revirtiendo, tradicionalmente los restos vegetales así como los sitios agrícolas y los espacios de recolección no conformaron un objeto de estudio en sí mismos. Esto resulta paradójico puesto que parte de este universo constituye la evidencia directa de la producción de alimentos, la que, a su vez, ha sustentado la existencia de modos de vida sedentarios, estratificados y complejos

3 Departamento de Antropología, Universidad de Chile. Ignacio Carrera Pinto 1045, Santiago, CHILE. Email: valentina.mandakovic@yahoo.es

4 Centro de Estudios Avanzados de Zonas Áridas (CEAZA). Casilla 554. Raúl Bitrán s/n, La Serena, CHILE. Email: amaldona@ userena.cl

5 Instituto de Ciencias Ambientales y Evolutivas, Facultad de Ciencias, Universidad Austral de Chile. Avda. Rector Eduardo Morales Miranda, Edificio Pugín s/n, Valdivia, CHILE. Email: mppena@gmail.com

6 Departamento de Biología, Universidad de Tarapacá. Av. General Velásquez 1775, Arica, CHILE. Email: eliana.belmonte@ gmail.com
(Núñez 1982). A la falta de contextualización de las evidencias agrícolas, se suma la excesiva atención dada a los pocos vegetales exóticos, los cuales han sido fetichizados y descontextualizados, derivando en explicaciones difusionistas que adjudican la complejidad social alcanzada, a los estímulos ideológicos y tecnológicos provistos por las poblaciones altiplánicas, por medio del establecimiento de colonias, o bien a través del control directo de las redes de intercambio (Núñez 1966, 1982; Rivera 1975, 1994). Con todo lo anterior, proponemos que para comprender el proceso local que sustenta dichas interacciones, los estudios deben iniciarse desde los contextos locales donde se recuperaron estos productos agrícolas y exóticos, así como también desde las continuidades heredadas del Arcaico (Lumbreras 2006; Staller 2006).

En este marco, documentaremos un bosque sepultado en la quebrada de Tarapacá, el cual debió constituir un importante espacio de recolección de maderas y alimentos durante la ocupación de las aldeas. De allí se obtuvieron muestras de troncos enterrados que fueron identificados taxonómicamente, datados por $\mathrm{C}^{14} \mathrm{y}$ analizados dendrocronológicamente. Asimismo, evaluaremos el rol de las plantas al interior de las aldeas, caracterizando la diversidad de rubros en los cuales se utilizan, relevando sus contextos de consumo y ahondando en los aspectos tecnológicos y sociales ligados a la producción de artefactos. Finalmente, reflexionaremos en torno a las experiencias humanas e imaginarios que se revelan en relación al mundo de las plantas, los cuales no constituyeron únicamente representaciones mentales al modo fenomenológico, sino que tuvieron consecuencias concretas en lo social, lo económico y lo ecológico (Ingold 2000; Castro y Romo 2006).

\section{* Reconstrucción paleoambiental y espacios DE OBTENCIÓN DE LAS PLANTAS}

La región de Tarapacá abarca un amplio espacio que comprende desde la quebrada de Camiña o Tana y el altiplano de Isluga por el norte, hasta el río Loa por el sur, entre la costa Pacífica y la Puna. Colinda por el norte con la región de Arica y por el sur con Atacama, vinculando los Valles Occidentales con la Circumpuna. No es casual que el lugar de emplazamiento de las aldeas formativas en esta región se halle en las desembocaduras de las quebradas endorreicas 


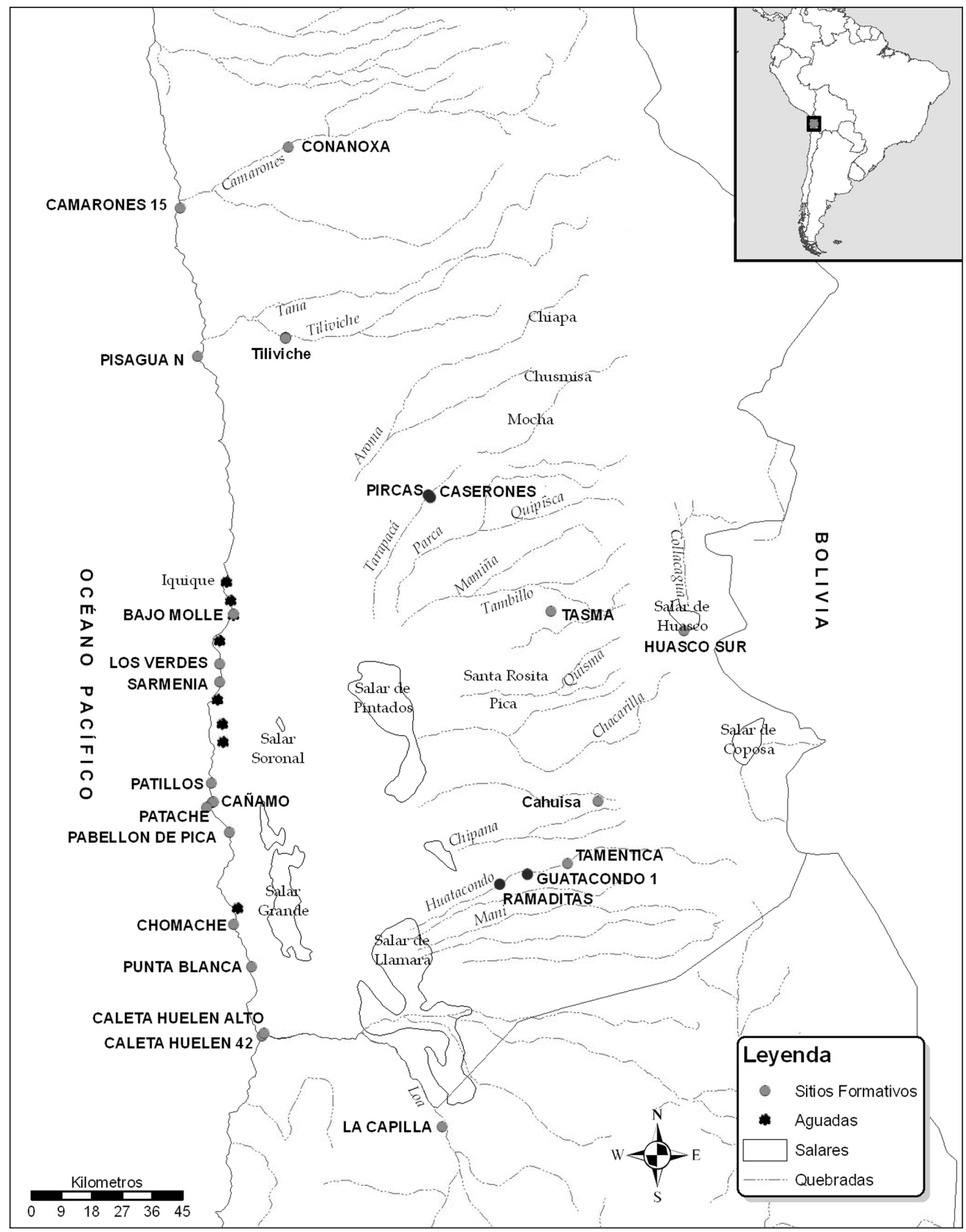

Figura 1. Sitios arqueológicos del período Formativo (ca. 1000 AC-900 DC) de la región de Tarapacá.

de la región, principalmente las de Tarapacá y Guatacondo. En dichos espacios, la cordillera de la Costa constituye una barrera infranqueable que los ríos que descienden desde la Puna no pueden traspasar. Al desaguar en la pampa, éstos propician un ambiente singular, donde las napas freáticas acumuladas durante el Cuaternario generaron ricos sue- los que permitieron sustentar los primeros experimentos agrícolas durante el Formativo, además de grandes extensiones de bosques de Prosopis que constituyeron fuentes de maderas, forraje y alimentos apreciadas por los indígenas desde tiempos arcaicos (Niemeyer 1961; True et al. 1970; Núñez 1979, 1982; Briones et al. 2005) (Figura 1). 
En función de lo anterior, operativamente reconocemos tres espacios de obtención de plantas en nuestra área de estudio: los bosques de la Pampa del Tamarugal, los valles que allí desaguan y los campos agrícolas aledaños a las aldeas. En primer lugar, la Pampa del Tamarugal constituye actualmente una enorme faja monótona de terrenos desérticos e improductivos, de $17.253 \mathrm{~km}^{2}$, debido a la depredación que sufrieron los bosques durante los inicios del ciclo salitrero, cuando se requerían enormes volúmenes de combustible para hacer funcionar el sistema de paradas (Bermúdez 1963; Couyoumdjian y Larraín 1975; Hidalgo 2009). Ya a fines del s. XIX, un estudio de factibilidad agrícola reconocía esta depredación y la consiguiente necesidad de repoblar el bosque de tamarugos (Billinghurts 1887 cit. en Castro 2004). Mucho después, en la década de 1960, este llamado lo concretó la Corporación de Fomento (CORFO) reforestando lo que actualmente constituyen las mayores extensiones verdes de la Pampa del Tamarugal. En otros lugares, como en La Tirana, los bosques depredados sobrevivieron en forma de renovales, mientras que en la quebrada de Tarapacá encontramos troncos muertos y hojarasca que afloran de una duna estabilizada junto al cementerio Tarapacá 40 (Tr-40).

Para dilucidar si este último bosque se encontraba vivo durante la ocupación de las aldeas, y en términos más amplios, contribuir con la caracterización paleoambiental de la Pampa del Tamarugal, se tomaron muestras de los troncos enterrados para ser analizados en términos dendrocronológicos, radiocarbónicos y taxonómicos (Baierd y Roselló 2005).

Como sabemos, el crecimiento de los árboles responde a un conjunto de factores ambientales interactuantes que determinan la estructura de sus anillos de crecimiento. Por ello, las series de crecimiento anual constituyen verdaderos bancos de datos naturales de gran valor climático, ecológico e histórico (Schweingruber 1988). Para evaluar la influencia del clima sobre el crecimiento radial de los árboles de la Pampa del Tamarugal, se compararon series anuales de ancho de anillo de muestras provenientes de los troncos enterrados (subfósiles) de Tr-4o con muestras provenientes de árboles vivos del género Prosopis. En relación a éstas últimas, se muestrearon 25 tamarugos (Prosopis tamarugo) cercanos al poblado de La Tirana, específicamente secciones transversales o rodelas de ramas y fustes que habían sido cortados previo al muestreo. Adicionalmente, se muestrearon 11 algarrobos (Prosopis alba) cercanos al poblado de Huarasiña, colectándose de cada uno de ellos un promedio de cuatro muestras que incluyen tanto tarugos de incremento mediante taladro como secciones transversales de ramas. Para las secciones, se trabajaron entre 1-3 radios por muestra, y solo un radio por tarugo de incremento. A lo largo de cada radio se asignó una fecha y se midió el ancho de cada anillo de crecimiento (precisión de $0.001 \mathrm{~mm}$ ), con lo cual se construyó una serie temporal de ancho de anillo. Las series de muestras vivas pueden ser fechadas con años calendario pues se conoce el año al cual corresponde el último anillo de crecimiento (Schulman 1956). Sobre éstas pueden ser fechadas las series de muestras muertas.

Con ello, se seleccionaron las series que presentaron un patrón común de variación interanual (cofechado), las cuales fueron estandarizadas y promediadas para obtener una cronología media por especie (Fritts 1976; Cook et al. 1990). De este modo, la extensión de las cronologías de las muestras vivas abarca 39 años para el algarrobo (1969-2007) y 79 años para el tamarugo (1929-2007). El corto período de estas cronologías no resultó suficiente para acoplar la cronología subfósil a un período calendario, quedando ésta con una cronología flotante que abarca 100 años (Tabla 1).

\begin{tabular}{|l|c|c|c|}
\hline & $\begin{array}{c}\text { P.alba } \\
\text { (muestras } \\
\text { vivas) }\end{array}$ & $\begin{array}{c}\text { Prosopis } \\
\text { (muestras } \\
\text { subfósiles) }\end{array}$ & $\begin{array}{c}\text { P. tamarugo } \\
\text { (muestras vivas } \\
\text { y muertas) }\end{array}$ \\
\hline $\begin{array}{l}\mathrm{N}^{\circ} \text { de individuos } \\
\text { muestreados }\end{array}$ & 11 & 40 & 25 \\
\hline $\begin{array}{l}\mathrm{N}^{\circ} \text { de muestras } \\
\text { procesadas }\end{array}$ & 37 & 48 & 42 \\
\hline $\begin{array}{l}\mathrm{N}^{\circ} \text { de series de } \\
\text { ancho de anillo } \\
\text { cofechadas }\end{array}$ & 23 & 0.536 & 20 \\
\hline $\begin{array}{l}\text { Intercorrelación } \\
\text { entre series }\end{array}$ & 0.586 & 100 & 0.561 \\
\hline $\begin{array}{l}\text { Años de la } \\
\text { cronología }\end{array}$ & flotante & $1929-2007$ \\
\hline Período cronología & $1969-2007$ & & 79 \\
\hline
\end{tabular}

Tabla 1. Resumen de las series analizadas de Prosopis alba (Huarasiña), Prosopis tamarugo (La Tirana) y Prosopis alba subfósil (Tarapacá 40). 


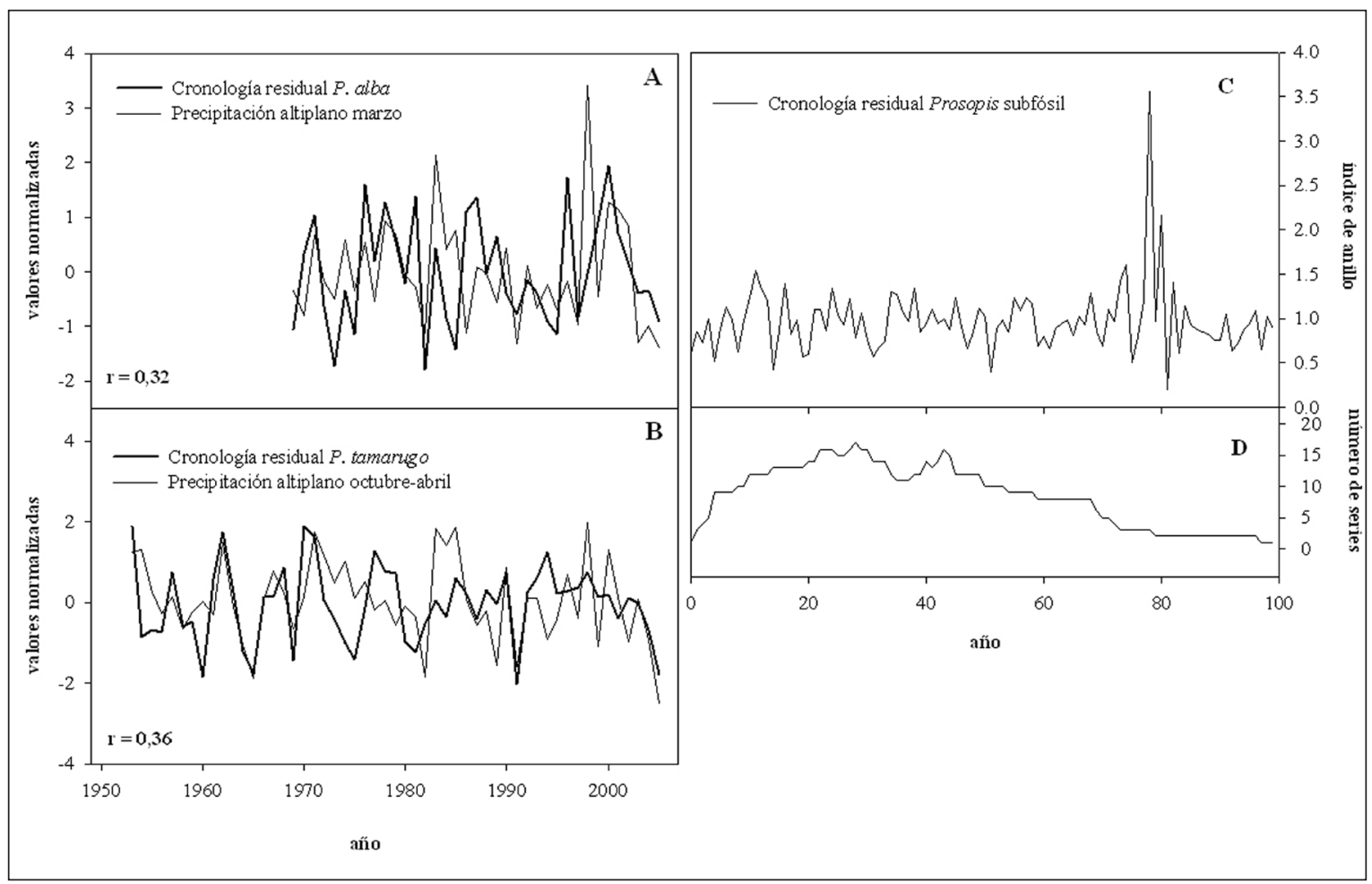

Figura 2. Función de correlación entra la cronología de ancho de anillo de Prosopis alba (A) y Prosopis tamarugo (B) con la precipitación del altiplano para el período común entre las series de anillo y clima. Considerando que las napas subterráneas de la Pampa del Tamarugal son recargadas con las lluvias provenientes del altiplano (Houston 2002) se realizó una función de correlación entre la cronología de $P$. tamarugo y la precipitación del altiplano para los meses de marzo para P. alba y octubre a abril para P. tamarugo, la cual coincide con el período de crecimiento de la especie. Los meses analizados se determinaron según la mejor correlación dada a nivel mensual y en grupos de meses. (C) Cronología flotante para las muestras subfósiles de Tarapacá 40. (D) Número de series por año con las cuales se desarrolló la cronología flotante.

Por otra parte, para evaluar la relación clima-crecimiento se realizaron funciones de correlación entre la cronología de ancho de anillo tanto de tamarugo y algarrobo con una serie regional de precipitación altiplánica de la región de Tarapacá que abarca 57 años (Dirección General de Aguas). Es relevante evaluar la relación con la precipitación altiplánica debido a que ésta es la principal fuente de recarga para el acuífero del Tamarugal y por lo tanto sería el mayor factor limitante para el crecimiento para las especies del género Prosopis (Houston 2002). Como era de esperar, los resultados sugieren una correlación entre el crecimiento radial de ambas especies y las precipitaciones del altiplano, específicamente del período octubre-abril para el tamarugo, y de marzo en el caso del algarrobo. Por su parte, la cronología flotante muestra una variabilidad dentro del mismo rango que la cronología de muestras vivas, excepto en un caso, en que se observa un rango de variación de ancho de anillo mayor al registrado en el presente, sugiriendo que en los años que abarca la cronología flotante hubo al menos un evento de precipitaciones de mayor intensidad que los registrados en las series actuales. No obstante, este último es sustentado por un número bajo de muestras, por lo que su interpretación en términos estadísticos debe considerarse con precaución (Figura 2).

Finalmente, las muestras de troncos subfósiles fueron identificadas a partir de cortes histológicos como algarrobo (Prosopis alba) (Díaz-Vaz, com. pers. 2013) y fechadas por radiocarbono en $\sim 1400$ años AP. De este modo, varios elementos de este análisis aportan a la comprensión de los sitios arqueológicos en cuestión. En primer 
lugar, la fecha obtenida es coincidente con la ocupación de las aldeas y el cementerio Tr-40. Al mismo tiempo, es posible pensar que las vainas de algarrobo comestibles presentes en los sitios debieron ser colectadas en este bosque. Por último, en términos dendrocronológicos, la presencia de anillos más gruesos dentro de la mencionada cronología flotante de 100 años estaría vinculada a mayores precipitaciones en el altiplano, lo cual daría cuenta de niveles de humedad mayores que los actuales $y$, en este sentido, una cobertura forestal más significativa.

En complemento, otros análisis paleoclimáticos realizados se refieren al estudio de polen contenido en paleomadrigueras de roedores del piso Tolar (3300-4000 m.snm), tanto en la latitud del salar del Huasco como en quebrada de Maní. Los primeros han dado como resultado un ambiente de mayor aridez que el actual para el Holoceno Medio (8000-3500 AP), un aumento notable de la humedad hacia 2200-1000 años AP, y nuevas condiciones de aridez para los últimos siglos (Maldonado y Uribe $2011 \mathrm{Ms}$ ). Los segundos estudios dan cuenta de la existencia de tres períodos más húmedos situados entre 2500-2040, 1615-1350 y 1050-680 años AP (Gayó et al. 2012). De esta manera, ambos trabajos muestran resultados coherentes con la dendrocronología efectuada en la Pampa del Tamarugal, que permiten concluir que el ambiente durante el Formativo Tardío e inicios del Intermedio Tardío (ca. 1000 DC) fue más húmedo que el actual y se vinculó a una mayor cobertura vegetacional de tolas en tierras altas y forestales en la pampa (García et al. 2011; Maldonado y Uribe 2011 Ms; Maldonado y González 2012 Ms). Con lo anterior, se valida lo planteado 40 años antes por Mostny (1971), quien a partir de la abundancia y tamaño de los troncos presentes en los sitios arqueológicos de Guatacondo, ya proponía que en el Formativo la situación climática debió ser mucho más favorable que en la actualidad.

Junto con los bosques, las quebradas que descienden desde la Puna y desaguan en la Pampa del Tamarugal constituyen un segundo espacio de obtención de plantas. Entre las más importantes se encuentran la quebrada de Aroma, Tarapacá, Juan de Morales, Quisma, Maní y Guatacondo, las cuales generan un alto contraste de humedad en relación a la monotonía del desierto.
Allí crece una amplia diversidad florística, conocida y aprovechada por las comunidades tarapaqueñas desde tiempos prehispánicos. Entre las especies arbóreas y arbustivas nativas más recurrentes encontramos: molle o pimiento (Schinus molle), chañar (Geoffroea decorticans), algarrobo (Prosopis alba), tamarugo (Prosopis tamarugo), visavisa (Trixis cacalioides), sapama (Ophryosporus pinifolius), tajtaja (Lophopappus tarapacanus) y brea o sorona (Tessaria absinthioides). Adyacente a la ribera de los ríos hay cortadera (Cortaderia atacamensis), cañaveral (Phragmites australis), junquillos (Scirpus atacamensis), totora (Typha angustifolia) y qosqosa (Equisetum giganteum) (Villagrán et al. 1999).

Por último, hay un tercer ámbito de obtención de plantas, dado por los sitios agrícolas aledaños a las aldeas formativas. Si bien la datación de estos espacios es compleja, sobre todo en el caso de la quebrada de Tarapacá donde las reocupaciones se han mantenido hasta tiempos recientes, existen varios indicadores que nos permiten proponer que dichos campos tendrían su origen en el Formativo. El primero y más obvio es la asociación espacial. En Tarapacá, las aldeas de Caserones y Pircas acceden directamente a sectores cultivados en el fondo de la quebrada, regados por un canal que toma el agua desde las vertientes de Huarasiña, ubicadas unos $2 \mathrm{~km}$ aguas arriba. En los sectores cultivados más altos, se preservan además, vestigios prehispánicos que no han sido alcanzados por los aluviones que descienden esporádicamente desde la Puna por efecto del invierno altiplánico.

La activación de los ríos producto de este último fenómeno, fue aprovechada para regar las más de 500 hás de campos de cultivo aledaños a las aldeas de Guatacondo I (G-1), Guatacondo 2 (G-2) y Guatacondo 3 o Ramaditas -siguiendo la nomenclatura de Rivera y colaboradores (1995-96)-, ubicadas aguas abajo del oasis de Tamentica. En este espacio no existen vertientes ni otros escurrimientos superficiales, por lo que el agua para riego necesariamente debió tomarse del lecho principal durante los meses de verano. La contemporaneidad con las aldeas formativas está nuevamente atestiguada por la asociación espacial, pero además, está reforzada por la presencia de materiales en superficie únicamente formativos como cerámica Loa Café Alisado (LCA) e instrumentos expeditivos de basalto negro similares a los descritos por Mostny (1971). 


\section{* Los sitios arqueológicos}

A continuación describiremos brevemente las aldeas donde habitaron quienes convivieron con las condiciones ambientales descritas e hicieron uso de los espacios mencionados. Dichas aldeas fueron primeramente trabajadas en la década del 1970 y reevaluadas desde el año 2005 por nuestro equipo.

\section{Aldea de Pircas}

Pircas se emplaza en la terraza norte de la quebrada de Tarapacá (1344 m.snm), al oriente del cementerio Tr-40 y del bosque sepultado, frente a Caserones, aguas abajo de la localidad actual de Huarasiña. Se trata de un asentamiento disperso, primeramente trabajado por Núñez (1984) quien registra y excava las estructuras del sector central, recuperando restos de maíz, algarrobo, poroto pallar, algodón, artefactos tallados en madera, hilados, capachos y cestos de fibra vegetal. La aldea se compone de recintos circulares y elipsoidales de carácter habitacional y de servicio, cementerios acotados, áreas ceremoniales delimitadas por muros periféricos, fosos de ofrendas y geoglifos (Núñez 1984; Urbina y Adán 2007).

En la reciente reevaluación del sitio se contabilizaron 56 conglomerados arquitectónicos equivalentes a 562 estructuras pircadas, dispuestos en una superficie de 90 hás, cuyos depósitos fueron fechados entre 370 AC y 500 DC (Urbina y Adán 2007). Junto con ello, se efectuó una recolección superficial del 10\% de las estructuras, dentro de las cuales se eligieron 18 (2.8\%) para ser excavadas, trazándose cuadrículas de 1 x 1 m en su interior.

En relación a los vegetales, se puede decir que es el tipo de resto más frecuente en los depósitos excavados, destacando los recintos 198 y 251, ambos con ocupaciones superpuestas. En el primero, ubicado en el sector central y más activo del sitio (Conjunto 1, sensu Núñez 1984), se detectaron tres momentos diferenciados (Méndez-Quirós 2012). Los niveles iniciales se vinculan a un piso de ocupación asociado a abundantes desechos de talla lítica, escasos fragmentos de cerámica LCA, maíz, algarrobo y quinoa de apariencia silvestre, restos de pescado y algunos coprolitos de camélidos. Sobre este contexto hubo una segunda ocupación en la cual disminuye abruptamente la talla lítica y se agregan algunas plumas así como restos ya mencionados para la capa anterior. Sobre ésta, se halló un fardo funerario envuelto en mantas, con turbante y amarrado con sogas de fibra vegetal que nos recuerdan las tumbas de Tr-40. Junto al fardo se halló una bolsa de cuero de lobo marino con pigmento, una aguja de espina de cactus, una máscara de felino en miniatura (vinculables a las miniaturas de $\operatorname{Tr}-40$ ), flores de totora, dos colgantes de madera antropomorfos, una preforma de tableta, una madera tallada perciforme y un posible instrumento de viento. Sobre el fardo se puso una capa de tallos de maíz y sobre éstos, continuó apareciendo maíz, algarrobo, cerámica LCA, así como virutas y carbón. El contexto fue fechado en 350-520 DC (Urbina et al. 2012). Por otra parte, en el recinto 251 se hallaron dos ocupaciones separadas por el derrumbe de un muro, en las cuales el material vegetal nuevamente fue lo más abundante. Allí se registraron una importante diversidad de tallos de brea, totora, así como restos de pescado y moluscos, cerámica, agujas de espina de cactus y los mismos colgantes de madera hallados en la estructura anterior (Méndez-Quirós 2012).

\section{Aldea de Caserones}

Se ubica sobre la terraza sur de la quebrada de Tarapacá, enfrentando a Pircas y al cementerio Tr-40 (1296 m.snm). Está compuesta por 645 estructuras aglutinadas circunscritas a un muro perimetral en una superficie de 3.75 hás. La larga ocupación del sitio se manifiesta en la historia arquitectónica del poblado, que posee tres conglomerados arquitectónicos principales, los cuales se fueron densificando y subdividiendo internamente. Los recintos son de planta ortogonal construidos con bloques de caliche, así como de andesita y basalto para las fundaciones. Asimismo, se visualizan improntas de postes de madera, ventanas y hornacinas, ramadas en el subsuelo que han sido interpretadas como techumbres colapsadas, estructuras de almacenaje y espacios amplios despejados, interpretados como espacios públicos. Las fechas obtenidas la sitúan en un rango temporal entre 20 y 1020 DC (Méndez-Quirós 2012; Pellegrino 2012; Urbina et al. 2012).

Caserones fue excavado en la década de 1960 en el marco del proyecto de cooperación internacional entre L. Núñez y la Universidad de California (UCLA), momento en el que se definió que el sitio habría sido poblado en tres 
oleadas. Los primeros habitantes habrían constituido poblaciones homogéneas convocadas a este lugar para llevar a cabo los primeros experimentos agrícolas. Posteriormente, se daría una nueva situación económica y social dada por estímulos de poblaciones venidas desde tierras altas, secundadas por poblaciones de la costa, coincidente con el momento en que proliferan los artefactos de pesca y recolección marina, además de múltiples artefactos elaborados en materias primas vegetales. Finalmente, la última oleada, hacia $1000 \mathrm{DC}$, se caracterizaría por una importante densificación de las áreas habitacionales a las cuales se vinculan los pozos de almacenaje que evidenciarían una sobreproducción alimentaria enfocada al intercambio (Núñez 1966, 1982; True 1980). Entre los cultivos registrados se menciona maíz, poroto pallar, zapallo, quinoa, maní, ají y algodón. Entre las especies silvestres, se encuentran algarrobo, totora, tamarugo, molle y pacay (Núñez 1966, 1974, 1979, 1982). Junto al análisis de macrorrestos, el de coprolitos humanos apoyaría el consumo de gran parte de los alimentos mencionados, aunque sin reiterar el protagonismo del algarrobo visible en la primera línea de evidencia (Kautz 1980).

Por nuestra parte, el trabajo arqueológico ha consistido en recolecciones superficiales en el 10\% de los recintos y excavaciones de unidades de $1 \mathrm{x} 1 \mathrm{~m}$ en 17 recintos, que equivalen al $6.7 \%$ del total. La larga ocupación del sitio, por casi mil años, se evidencia en la profundidad de los depósitos, los cuales fluctúan entre 10 y $81 \mathrm{~cm}$ (promediando $48 \mathrm{~cm}$ ). Esta variabilidad está acrecentada por los pozos de almacenaje que aumentan el potencial estratigráfico en varios de los depósitos (Méndez-Quirós 2012). Como en el caso de Pircas, los restos vegetales constituyen el material más abundante. Asimismo, ciertos depósitos muestran evidentes superposiciones así como cambios de funcionalidad de las estructuras a lo largo del tiempo. Por ejemplo, el estrato inicial del recinto 516 corresponde a un piso ocupacional asociado a elementos de molienda, algarrobo, brea, maíz y calabaza, restos de pescado y cerámica formativa tardía. Luego de un hiato de abandono, el recinto se reactiva con una potente ocupación doméstica combinada con un uso como corral. En este nivel, la cerámica Pica Charcollo (en adelante PCH) del Intermedio Tardío sobrepasa al componente Formativo Tardío, lo que se asocia a abundantes conjuntos vegetales, superando las mil semillas de algarrobo, junto a maíz, madera y cañas, además de carbón y una viruta. En la parte superior del depósito hay restos de una posible techumbre derrumbada marcando el fin de la ocupación (Méndez-Quirós 2012).

En la estructura 314, correspondiente a una de las dos plazas cerradas de Caserones, las ocupaciones se intercalan con evidencias de derrumbe. Se registra una ocupación inicial con desechos de sílice y andesita, algarrobo, maíz, brea, molle, bivalvos y gastrópodos, junto a escasa cerámica del Formativo Tardío y abundante carbón. Este es el único momento donde se verifica nítidamente la función original del recinto correspondiente a un espacio público de uso festivo (Vidal 2009). Luego de sucesivos derrumbes verificamos un segundo momento donde el recinto se reutilizó como corral (Méndez-Quirós 2012). Finalmente, la estructura 7, que corresponde a un espacio residencial asociado a un pozo de almacenaje, inicia su ocupación con una alta densidad artefactual, principalmente cerámica del Formativo Tardío, y una baja proporción de cerámica $\mathrm{PCH}$. Del pozo de almacenaje provienen más de 40 corontas de maíz, además de molle, algarrobo, restos de pescado, entre otros, sobre los cuales se halló una proporción no menor de heces humanas con alto contenido de algarrobo que podrían evidenciar un uso posterior como baño. Finalmente, sobre la ocupación anterior se halló una nueva concentración de materiales, ahora asociados con cerámica predominantemente del Intermedio Tardío.

\section{Cementerio Tarapacá 40}

Si bien los contextos de dicho cementerio no formaron parte del universo material de nuestro análisis, su importancia para establecer comparaciones con los vegetales de las aldeas merece una pequeña reseña. Fue excavado por Núñez en la década de 1970, quien propone dos oleadas poblacionales representadas en los sectores A y B, que estarían vinculadas a los habitantes de Caserones, tanto a su momento inicial más costero como a las oleadas más tardías vinculadas a Tiwanaku (Núñez 1974, 1979; Núñez y Santoro 2011). Se describen tumbas demarcadas por postes con cuerpos flectados, cubiertos por pieles de aves, hallados en grandes cestos. Además, algunos fardos se encuentran envueltos por sogas gruesas o zunchos que aparentemente sirvieron para ser movilizados. Asociados a ellos, se encontraron decenas de miniaturas de cestos, textiles y cerámica, además de palomitas de 
maíz y quinoa en cestos decorados, capachos, bolsas en fibra vegetal, desconchadores, valvas de marisco con pigmento, collares, tubos y espátulas, destacando un tubo con decoración volumétrica que presenta una cabeza humana y un felino reptando hacia la boquilla, entre otros (Catalán 2010 Ms; Agüero 2012). Desde la bioantropología, se concluyó que los cuerpos mostraban edades entre o y 50 años, aunque con una baja mortalidad infantil (seis casos). Fue común encontrar deformación craneana, traumas por violencia interpersonal, robustez generalizada adjudicada a la movilidad, así como lesiones en el área cervical conferidas al sobrepeso por uso de capacho. Por último, los cuerpos muestran poco desgaste dental y la presencia de caries vinculadas al consumo de carbohidratos (Herrera 2010). Previamente, Allison (com. pers. en Briones 1985) efectuó análisis a los contenidos estomacales de algunas momias, dando cuenta de un excesivo consumo de algarrobo que en algunos casos provocó megacolon o colon dilatado. Las fechas obtenidas para este cementerio son $290 \pm 90$ DC (Núñez 1969) y $360 \pm 170$ DC (Oakland 2000).

\section{Aldea de Ramaditas}

Esta aldea fue registrada por Mostny (1971), quien la llamó G-2, y luego por Rivera y colaboradores (1995-96) denominándola G-III. Se emplaza en la desembocadura de la quebrada de Guatacondo, $150 \mathrm{~m}$ al norte del lecho principal, a $1115 \mathrm{~m} . \mathrm{snm}$ ). Posee un patrón disperso que recuerda a Pircas. Está conformada por tres conglomerados arquitectónicos principales junto a estructuras pircadas dispersas al exterior de estos conjuntos, utilizando una superficie de 9.2 hás. Los muros fueron construidos en piedra y adobe, presentando algunos de ellos enlucidos de barro en los cuales se han registrado rostros antropomorfos muy simples modelados con los dedos cuando el barro aún estaba fresco. Se contabilizó un total de 83 recintos de carácter doméstico, algunos de ellos con accesos, ventanas, hornacinas, improntas de vigas $y / 0$ grandes postes centrales. Los fechados obtenidos recientemente sitúan su ocupación entre 380 AC y 80 DC (Urbina et al. 2012).

En las primeras excavaciones realizadas por Rivera se detectó una alta diversidad de especies vegetales, entre ellas maíz (Zea mays) y papa (Solanum tuberosum), restos de especies arbóreas como algarrobo (Prosopis sp.), diversas herbáceas determinadas a nivel genérico como Chenopodium sp., Atriplex sp., Cercidium sp., Euphorbia sp., Plantago sp. y Sphaeralcea sp. Junto a ellos, se describe una serie de recursos vegetales no especificados que se agrupan en las categorías de "palitos", "cuerdas" y "maderas". Entre los microrrestos, destaca la presencia de polen de Chenoam (Chenopodiaceae-Amaranthaceae), interpretándose que fue consumido en grandes cantidades. Asimismo, identifica fitolitos mayoritariamente de Chenopodium, y en menor medida Zea mays. Por último, en los almidones predomina Zea mays y en una menor proporción Solanum tuberosum, indicativo del consumo de maíz y papas, respectivamente (Rivera et al. 1995-96; Rivera 2002).

La intervención arqueológica reciente consistió, como en los sitios anteriores, en la recolección superficial del 10\% de los recintos y la excavación de siete de ellos (8.4\% del total) a través de cuadrículas 1 x $1 \mathrm{~m}$. Adicionalmente se recolectó la totalidad del material cultural presente en la superficie del sistema de campos 1, aledaño al conjunto habitacional 1, del cual se seleccionaron los canchones 3, 10 y 16 para la realización de pozos de sondeo de 50 x 50 $\mathrm{cm}$, los cuales no dieron resultados positivos en términos de macrorrestos. La excavación evidenció que la ocupación de Ramaditas fue muy efímera, representada por una delgada capa presente solo en algunos recintos, a la que se asocian escasos desechos líticos y carpos de algarrobo.

\section{Aldea de Guatacondo}

Los trabajos en la aldea Guatacondo se inician en 1970 con el reconocimiento que realiza Mostny (1971), denominándola G-1, y luego con la excavación que realizan los investigadores de la UCLA. El sitio se emplaza sobre una terraza fluvial, entre dos brazos de la quebrada. Se trata de una aldea aglutinada compuesta por 177 recintos circulares dispuestos en torno a una plaza central de gran tamaño con un monolito central, ocupando una superficie total de 0.77 há. Se reconocieron estructuras habitacionales, cocinas y probablemente patios, interconectados internamente con recintos tipo bodega y pozos cavados que permiten señalar una importante capacidad de almacenaje (Urbina et al. 2012). La construcción es principalmente de adobe con enlucido de barro destacando en un sector los adobes ovalados moldeados con la mano. Comparte también con Ramaditas las improntas de vigas ancladas a los muros, sobre las cuales debieron 
de ponerse ramadas, y los postes centrales y laterales al interior de los recintos, incluyendo la plaza. El rango temporal de la aldea se sitúa entre 340 AC y 70 DC (Urbina et al. 2012).

En relación a los vegetales obtenidos en las primeras excavaciones, destaca la recolección de algarrobo y el cultivo de calabaza, poroto pallar y maíz, con una fecha de 90 DC (Núñez 1979). En complemento, se analizó un total de 84 corontas de maíz (Zea mays) que se vinculan a las variedades harinoso tarapaqueño, chulpi y chucutuno chico (James 1980). Por último, el análisis de residuos de artefactos de molienda dio como resultado una asociación con algarrobo y no con cultivos. De esta manera, el algarrobo se presenta como la especie mayormente representada y de mayor distribución en el asentamiento, confirmando una explotación intensiva de este recurso (James 1980).

Como en las aldeas anteriores, nuestro trabajo arqueológico consistió en la recolección del 10\% de los recintos y la excavación de cuadrículas 1 x 1 m en ocho (4.5\% del total). Los depósitos evidencian una sola y clara ocupación, de donde se extrajeron restos de algarrobo, maíz, calabaza, desechos líticos, restos de pescado y cerámica LCA.

\section{* Criterios metodológicos para abordar} EL MATERIAL VEGETAL

La hiperaridez propia del desierto en el que se emplazan las aldeas, permite una excelente preservación de los restos orgánicos, los cuales al deshidratarse resguardan rasgos diagnósticos que pueden ser comparados con material de referencia actual. Ello, en definitiva, permite sustentar un análisis basado en criterios macroscópicos, estableciendo una diferencia importante con respecto a las tierras altas o los valles del oriente andino, donde la preservación generalmente es reducida y es necesario llevar a cabo análisis a nivel microscópico.

Los restos analizados fueron obtenidos de harneros (malla 2 y $3 \mathrm{~mm}$ ) y por flotación. Se flotaron muestras de suelo de todos los rasgos detectados en las excavaciones, así como de ciertos depósitos completos que nos permitieran documentar cambios en las ocupaciones, sobre todo en el caso de Caserones y Pircas. Las muestras extraídas correspondieron idealmente a 1 lt de sedimento por nivel estratigráfico. El volumen de sedimentos flotados alcanzó un total de 142.9 lt, de los cuales 9.8 provienen de Pircas, 96.1 de Caserones, 29.05 de Ramaditas y 8 de Guatacondo.

Tanto los ecofactos obtenidos de harnero como por flotación fueron separados de acuerdo al tipo de evidencia, distinguiendo frutos, semillas, tallos, hojas, inflorescencias, maderas, cortezas y carbón. Para los carporrestos se llevó a cabo una cuantificación basada en el número mínimo de individuos (NMI), mientras que en los demás restos se aplicó una cuantificación por rangos, clasificándose como "abundante" cuando hubo más de 20 fragmentos, "medio" cuando hubo más de 10, y "escaso" cuando la muestra fue menor a ese número. La identificación taxonómica se realizó a partir de su comparación con ejemplares actuales de referencia (colección de los autores), utilizando lupa binocular (con aumentos hasta 45x) cuando fue necesario. Entre los carporrestos recuperados por flotación se reconocieron semillas de herbáceas locales, que crecen al interior de los sitios y poseen semillas muy pequeñas y livianas de fácil dispersión, por lo cual su ingreso al contexto arqueológico debe explicarse por la acción del viento más que por la acción humana y, en este sentido, fueron eliminadas del análisis. Estas corresponden a piyaya o cachiyuyo (Atriplex sp.), oreja de perro (Cistanthe sp.), oreja de ratón (Exodeconus integrifolius), malva (Tarasa operculata), kauchal (Tiquilia atacamensis), semillas del género Maleshervia sp., Scirpus sp. y Criptantha sp., así como otras pertenecientes a las familias de asteráceas, chenopodiáceas, poáceas o gramíneas y verbenáceas.

Por otra parte, los artefactos constituyen una categoría amplia, donde incluimos todo soporte vegetal con alguna intervención antrópica. De este modo, encontramos artefactos con muy distintos grados de formatización, incluyendo instrumentos terminados, agotados, preformas y desechos de talla. Todos ellos fueron obtenidos directamente o a través de harneros, los mismos utilizados para la obtención del resto de los materiales. El análisis de laboratorio estuvo guiado por un criterio tecnológico donde cada pieza fue registrada de forma independiente. En el caso de artefactos terminados, agotados y preformas, éstos fueron dimensionados y documentados de acuerdo 
a su materia prima y la presencia de huellas de manufactura y uso. En el caso particular de Caserones, realizamos cortes histológicos de cuatro instrumentos con el fin de conocer las especies usadas para su fabricación.

Por su parte, los desechos de talla en madera o virutas fueron dimensionados en términos de longitud y espesor, y registrados de acuerdo a su posible materia prima (al menos arbustiva o arbórea), presencia de corteza (ausente, parcial o total) y tipo de astillamiento (desbaste primario o secundario). En relación a esto último, se definieron como virutas primarias aquellas que mostraron corteza en su cara anterior y cicatrices lineales paralelas producidas por la percusión en su cara posterior. Estas cicatrices lineales paralelas cortan diagonal o transversalmente las venas naturales de la madera y, de esta manera, permiten distinguirlas de las astillas naturales que se desprenden por deshidratación, ya que éstas lo hacen siguiendo justamente el curso de las mismas venas. Finalmente, los atributos utilizados para definir las virutas secundarias, consideró el mismo criterio para la cara posterior y la presencia del negativo del astillamiento previo en su cara anterior (García et al. 2009).

\section{* Las plantas como alimentos}

Los restos de alimento analizados provienen de fogones domésticos, pozos de almacenaje ubicados al interior de los recintos excavados y de un contexto ceremonial (tumba del recinto 198 de Pircas). Los alimentos de origen silvestre fueron identificados como algarrobo (Prosopis sp.), molle (Schinus molle), chañar (Geoffroea decorticans), amaranto (Amaranthus sp.) y puskayo o tunilla (Opuntia sp.), mientras que los cultivados corresponden a maíz (Zea mays), calabaza (Lagenaria siceraria), zapallo (Cucurbita sp.), quinoa (Chenopodium quinoa), pallar (Phaseolus lunatus), poroto (Phaseolus vulgaris) y maní (Arachis hypogaea). Todos ellos son posibles de obtener (recolectar o cultivar) en el entorno de los sitios, a excepción de la tunilla que corresponde a una cactácea de la precordillera (2700-3000 m.snm), y el maní que se cultiva en las yungas orientales (Tabla 2). Como veremos a continuación, algunas de estas especies poseen otros usos más allá del alimentario (documentados etnográficamente), los cuales no siempre dejan huella en el registro arqueológico (p.e., medicinal, tintóreo, forraje).
El alimento más representado, que está presente en las cuatro aldeas, es el algarrobo (Prosopis sp.), contabilizándose un total de 18.284 endocarpos, además de algunas vainas, hojas, espinas, ramitas y madera. La alta frecuencia de endocarpos en contraste con el bajo número de vainas, evidencia la importancia que tuvo la preparación de harinas, ya sea para elaborar masas o bebidas (chicha, conocida como aloja o guarapo). Ello se refuerza con los resultados obtenidos por James (1980) sobre la importancia del algarrobo en la molienda de Guatacondo. Como veremos, el algarrobo también fue apreciado por su valor artesanal y constructivo, y probablemente por otros usos (p.e., tintóreo, forraje) que no dejan huellas en el registro arqueológico. Destaca su concentración sobre todo en los pisos habitacionales de las aldeas de Caserones y Pircas, disminuyendo en Guatacondo, y siendo muy exiguo en Ramaditas. En general, y como han establecido las investigaciones previas, el protagonismo del algarrobo en todos los niveles estratigráficos excavados demuestra que fue un alimento básico para las comunidades formativas de Tarapacá. En este sentido, el algarrobo fue sin lugar a dudas un recurso abundante, fácilmente recolectable y almacenado por sus múltiples usos (Villagrán y Castro 2004).

En menor medida, los frutos de molle (Schinus molle) y chañar (Geoffroea decorticans) también son importantes. Del primero, se recuperaron 73 drupas en Caserones y una en Pircas, mientras que del segundo se registraron nueve carozos en Pircas y dos en Caserones. En las aldeas de la quebrada de Guatacondo, estos recursos están ausentes. Al igual que el algarrobo, estos árboles constituyen especies frecuentes en las quebradas donde se emplazan los sitios. Su importancia alimentaria está documentada etnográficamente, donde el molle se consume con azúcar y sirve para elaborar chicha, mientras que los frutos del chañar son utilizados para hacer arrope y postres (Villagrán y Castro 2004).

Por otra parte, hemos registrado una semilla carbonizada de tunilla (Opuntia sp.) en la aldea Guatacondo. Las especies de Opuntia se vinculan a cactáceas rastreras frecuentes en el piso precordillerano (2700-3000 m.snm) de todo el Norte Grande (Hoffmann 1989; Villagrán y Castro 2004). Etnográficamente, se reconoce principalmente el uso comestible, medicinal y forrajero de sus frutos. Son de sabor ácido como el limón, perfectamente 
comestible al natural y útiles para combatir la sed. Junto a los frutos, la pulpa se utiliza para preparar mermeladas, melcochas, jaleas y bebidas, y algunas raíces también son comestibles (Villagrán et al. 1999; Villagrán y Castro 2004; Pardo y Pizarro 2005; Novoa 2006) (Figura 3).

Finalmente, otros alimentos silvestres podrían estar dados por los rizomas, brotes tiernos y flores de juncos (Scirpus sp.) y totoras (Typha sp.) (Pardo y Pizarro 2005), no obstante no los hemos registrado en los contextos arqueológicos, sino únicamente sus tallos, los cuales hemos vinculado a materias primas para elaborar cordelería y esteras. La única excepción en este sentido, la constituyen las flores de totora halladas en el contexto funerario de Pircas, las cuales debieron ser obsequiadas tanto por su valor ornamental como comestible.

Junto con los frutos silvestres recolectados en los bosques o al interior de las quebradas, el producto agrícola comestible más representado en el registro arqueológico

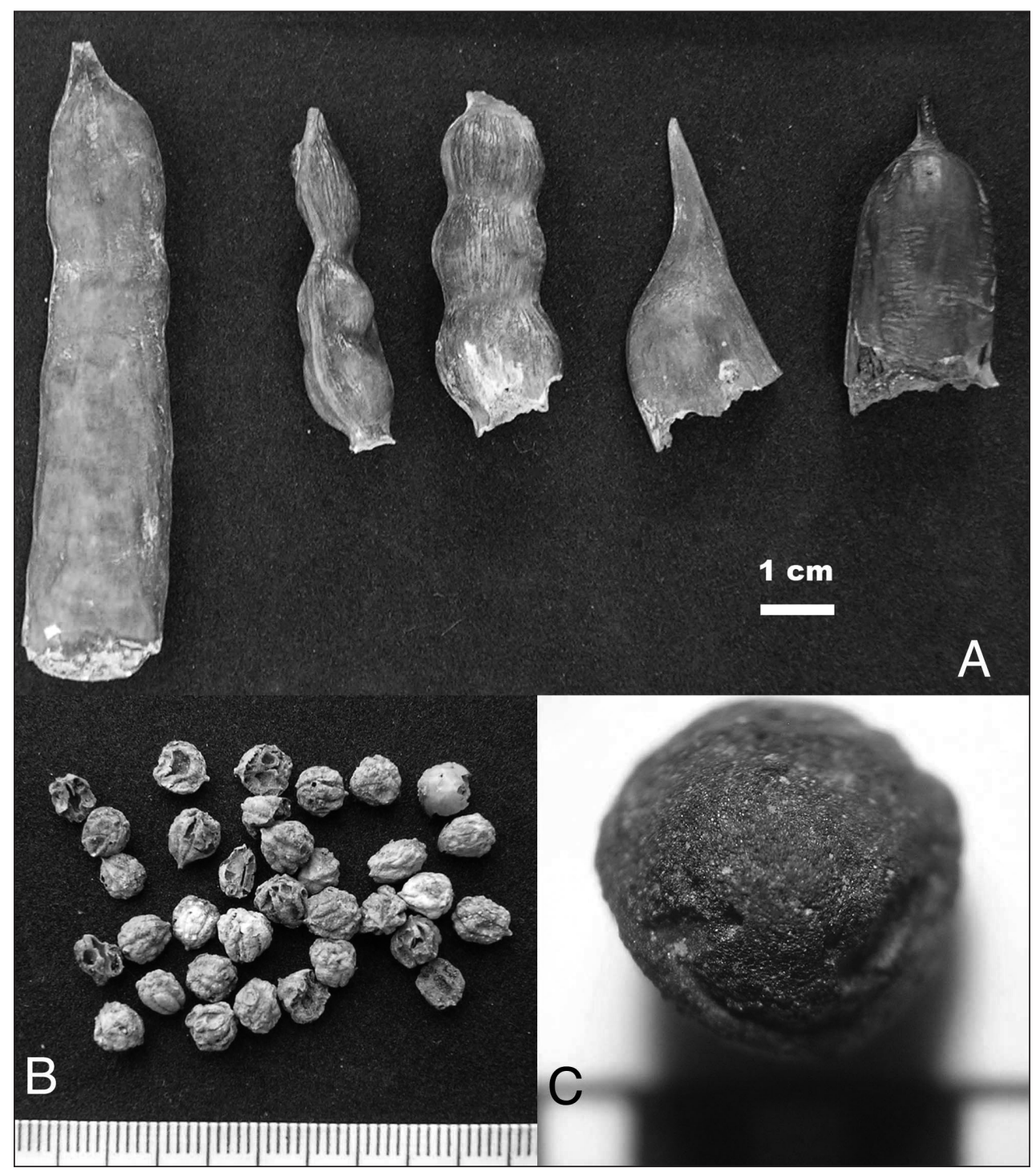

Figura 3. Plantas alimenticias de origen silvestre: a) Vainas de algarrobo (Prosopis sp.), Caserones; b) Frutos de molle (Schinus molle), Caserones; c) Semilla de puskayo o tunilla (Opuntia sp.), aldea Guatancondo 1. 
es el maíz (Zea mays), presente en Caserones, Pircas y Guatacondo. Esta especie está representada por 410 corontas, 1180 granos o cariopses, así como hojas, tallos y espigas, estos últimos únicamente en las aldeas de la quebrada de Tarapacá, entre los cuales más del $95 \%$ se concentra en Caserones, especialmente en los pozos de almacenaje (recinto 7). El ejemplar extraído del recinto 3 nivel 4 de Guatacondo, fue datado en cal. 50 AC-70 DC (Urbina et al. 2012).

Por otra parte, las cáscaras o pericarpio de calabaza (Lagenaria siceraria) suman 54 fragmentos, de los cuales más del $90 \%$ se concentra nuevamente en Caserones. En relación a los otros sitios, en Guatacondo se registraron tres fragmentos, mientras que en Pircas solo uno. Uno de los ejemplares extraídos del segundo sitio (recinto 153, nivel 7) fue fechado en cal. 90 AC-60 DC (Urbina et al. 2012). Entre las calabazas, hay variedades dulces y amargas, dentro de las cuales las comestibles se consumen cuando los frutos aún están inmaduros, ya que al madurar, el pericarpio aumenta su grosor y se endurece, mientras que el mesocarpo o sección carnosa se reabsorbe y desaparece (Lema 2009).

Asimismo, se registró un poroto pallar (Phaseolus lunatus) y dos porotos comunes (Phaseolus vulgaris) en Ca- serones y Pircas. Una distribución diferente muestran los restos de quinoa cultivada (Chenopodium quinoa) que fueron hallados en similares cantidades en Guatacondo y Caserones. En el primero, los restos se distribuyen en dos de los ocho recintos excavados mientras que en Caserones están presentes en nueve de los 17 recintos. La datación directa sobre una porción de los ejemplares de Guatacondo, recinto 3 nivel 5 (inicial), arrojó una fecha de cal. 160 AC-20 DC (Urbina et al. 2012). Por su parte, los restos de amaranto (Amaranthus sp.) tendrían usos similares a los de quinoa (Chenopodium quinoa). Se contabilizó un total de 500 semillas provenientes de Caserones, ninguna de ellas carbonizada, distribuidas igualmente en nueve de los 17 recintos excavados. No tenemos certeza si se trata o no de una especie cultivada. Otros restos complejos de clasificar son las semillas determinadas como Chenopodium sp., que se refieren a quinoa de apariencia silvestre asociada al fardo funerario de Pircas (Figura 4).

Finalmente, registramos dos fragmentos de cáscara de maní (Arachis hypogaea) en la superficie de Caserones, hallazgo que si bien es dudoso por no estar en posición estratigráfica reitera la mención previa hecha por Núñez (1982).

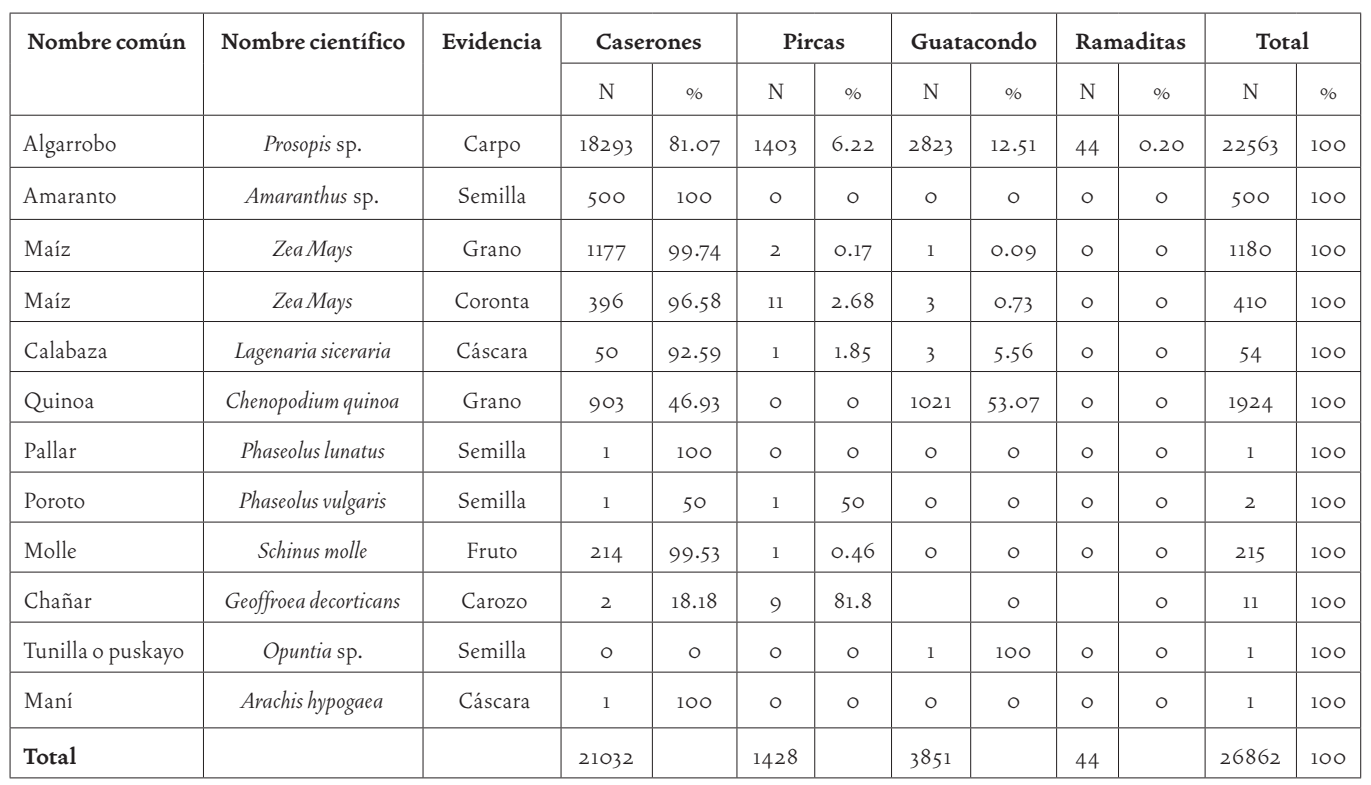

Tabla 2. Plantas alimenticias presentes en las aldeas estudiadas. 


\section{* Las plantas como materias primas}

En términos generales, la mayor parte de los artefactos y desechos provienen de niveles estratigráficos asociados a contextos domésticos. El total analizado suma 93 artefactos, de los cuales 49 se hallan en Pircas, 41 en Caserones y tres en Guatacondo. En función de su materia prima, un $57 \%$ corresponde a artefactos elaborados en fibra vegetal, principalmente cordelería, un $22 \%$ a tallados e incisos en madera, un $19 \%$ a artefactos en espinas y un $1 \%$ corresponde tanto a cuentas elaboradas en semillas como a calabazas con algún tipo de intervención. Como podemos apreciar, el conjunto presenta alta variación formal así como una desigual inversión de energía en sus manufacturas (Tabla 3).

\section{Artefactos en madera}

En las aldeas estudiadas, la madera fue sin duda un recurso prioritario al cual la arqueología le ha prestado poca atención. Está presente en las cuatro aldeas en for- ma de ecofactos, elementos de construcción, así como en herramientas que suman un total de 20 , distribuidas en Caserones, Pircas y Guatacondo. Por una parte, los artefactos expeditivos suman nueve ( $45 \%$ ) y se definen por ser elaborados al momento de ser usados y luego rápidamente descartados. Corresponden a palos aguzados, palos cortados, un palo inciso, un palo de brea (Tessaria absinthioides) embarrilado y un fragmento de madera cortado con forma cuadrangular (Figura 5).

Por otra parte, los artefactos formatizados suman 11, entre los cuales encontramos un astil en Caserones, cinco colgantes antropomorfos elaborados de manera similar, una preforma de cuchara, una preforma de tableta o tablilla, una madera tallada perciforme y dos piezas talladas con forma semidiscoidal exactamente iguales a las de Pircas. El astil fue tallado en una vara de brea (Tessaria absinthioides) de $30 \mathrm{~cm}$ de largo y uno de diámetro. En relación a los colgantes, éstos corresponden a piezas de madera de $7 \mathrm{~cm}$ de largo, con un rostro antropomorfo frontal en la parte superior, exactos a los recuperados

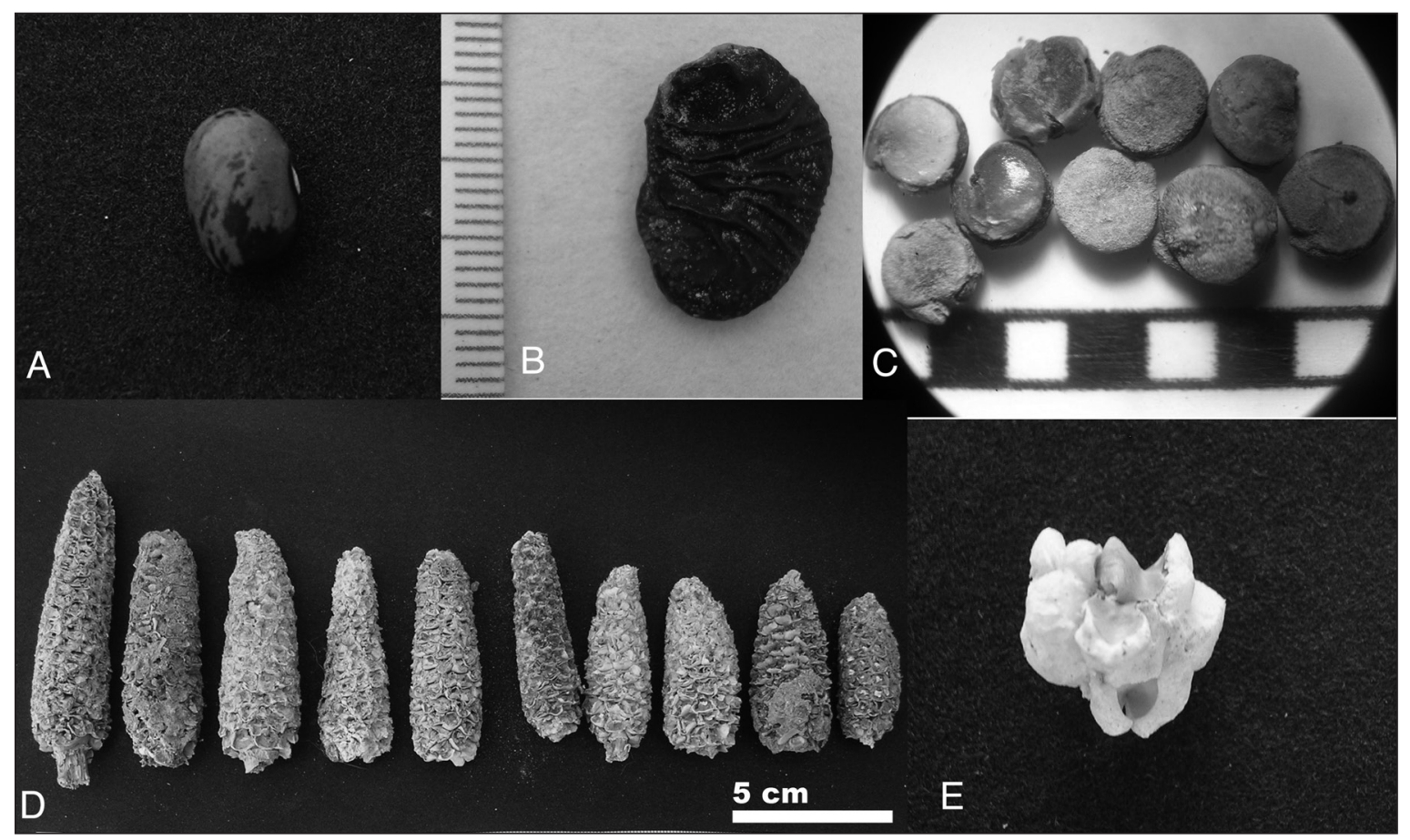

Figura 4. Plantas alimenticias de origen cultivado: a) Poroto común (Phaseolus vulgaris), Pircas; b) Poroto pallar (Phaseolus lunatus), Caserones; c) Granos de quinoa (Chenopodium quinoa), Guatacondo 1; d) Corontas de maíz (Zea mays), Caserones; e) Palomitas de maíz, Caserones. 


\begin{tabular}{|c|c|c|c|c|c|c|c|}
\hline \multirow{2}{*}{\multicolumn{2}{|c|}{ Materia prima }} & \multirow{3}{*}{$\begin{array}{c}\text { Artefacto } \\
\text { Palo aguzado }\end{array}$} & \multirow{3}{*}{ Caserones } & \multirow{3}{*}{$\begin{array}{c}\text { Pircas } \\
1 \\
\end{array}$} & \multirow{3}{*}{$\begin{array}{c}\text { Guatacondo } \\
1 \\
\end{array}$} & \multicolumn{2}{|c|}{ Total } \\
\hline & & & & & & \multirow{2}{*}{$\begin{array}{l}\mathbf{N} \\
2 \\
\end{array}$} & \multirow{2}{*}{$\begin{array}{r}\% \\
2.17 \\
\end{array}$} \\
\hline \multirow{11}{*}{ Madera } & \multirow{5}{*}{ Expeditivos } & & & & & & \\
\hline & & Palo cortado & 3 & & 1 & 4 & 4.35 \\
\hline & & Palo inciso & & 1 & & 1 & 1.09 \\
\hline & & Palo embarrilado & 1 & & & 1 & 1.09 \\
\hline & & Paralelepípedo de madera & & 1 & & 1 & 1.09 \\
\hline & \multirow{6}{*}{ Formatizados } & Colgantes antropomorfos y preformas & & 5 & & 5 & 5.43 \\
\hline & & Astil & 1 & & & 1 & 1.09 \\
\hline & & Preforma de tableta & & 1 & & 1 & 1.09 \\
\hline & & Preforma de cuchara & & 1 & & 1 & 1.09 \\
\hline & & Madera perciforme & & 1 & & 1 & 1.09 \\
\hline & & Madera semi discoidal perforada & & 2 & & 2 & 2.17 \\
\hline \multirow{7}{*}{\multicolumn{2}{|c|}{ Fibra vegetal }} & Cordelería (fragmentos) & 18 & 24 & 1 & 43 & 46.74 \\
\hline & & Estera & & 1 & & 1 & 1.09 \\
\hline & & Ovillo & & 2 & & 2 & 2.17 \\
\hline & & Tallo embarrilado & 1 & & & 1 & 1.09 \\
\hline & & Caña aguzada & 2 & 1 & & 3 & 3.26 \\
\hline & & Caña embarrilada & 1 & & & 1 & 1.09 \\
\hline & & Caña agujereada & 2 & & & 2 & 2.17 \\
\hline \multirow{2}{*}{\multicolumn{2}{|c|}{ Espinas de cactus }} & Agujas y preformas & 5 & 8 & & 13 & 14.13 \\
\hline & & Espina embarrilada & 1 & & & 1 & 1.09 \\
\hline \multicolumn{2}{|c|}{ Espina de algarrobo } & Espina desbastada & 4 & & & 4 & $4 \cdot 35$ \\
\hline \multicolumn{2}{|c|}{ Semilla } & Cuenta discoidal & 1 & & & 1 & 1.09 \\
\hline \multicolumn{2}{|c|}{ Calabaza } & Fragmento con pigmento rojo & 1 & & & & \\
\hline \multicolumn{3}{|l|}{ Total } & 41 & 49 & 3 & 93 & 100 \\
\hline
\end{tabular}

Tabla 3. Cantidad de artefactos elaborados en materias primas vegetales.

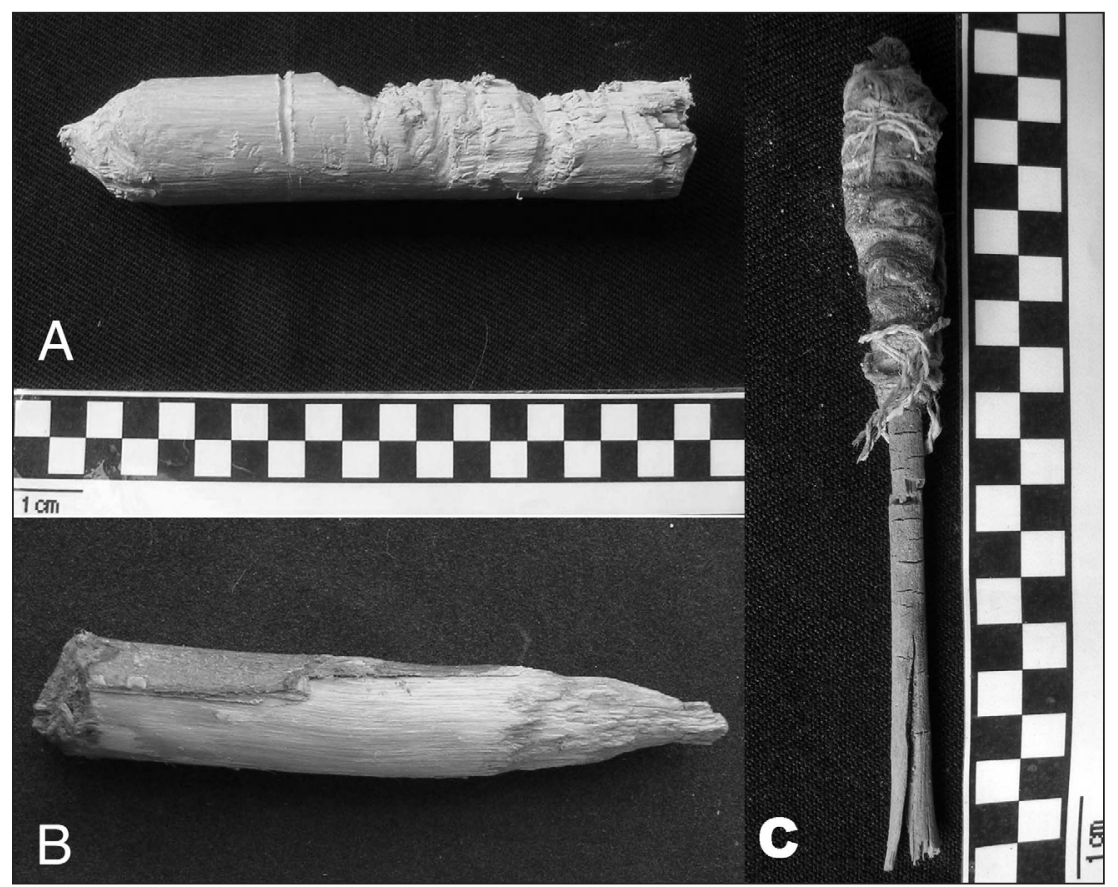

Figura 5. Artefactos expeditivos tallados en madera: a) Palo aguzado, Pircas; b) Palo aguzado, Caserones; c) Tallo de brea (Tessaria absinthioides) embarrilado con fibras de camélido. 
previamente por Núñez (1984). Poseen una perforación diagonal desde la cara posterior del rostro hasta el extremo superior, rasgo que permitió a Núñez (1984) definirlo como colgante. Presentan un rebaje en la porción central del eje así como una serie de incisiones lineales paralelas y convergentes que configuran lo que consideramos el cuerpo del personaje (Figura 6). Dos de las cinco piezas estudiadas por nosotros se encuentran completas, una constituye una preforma en la cual no fue tallado el rostro, mientras que dos ejemplares se encuentran fragmentados, uno de ellos embarrilado con fibra de camélido. Por último, la sorprendente estandarización de estos últimos objetos nos señalan un saber hacer, una práctica que puede ser vinculada a una tradición del tallado de la madera, la cual una vez entendida en sus cualidades y obtenido las habilidades para trabajarla, permite la fabricación "en serie" de los objetos por distintos artesanos. Dichos artefactos fueron recuperados de los recintos 198 y 251, ya mencionados.

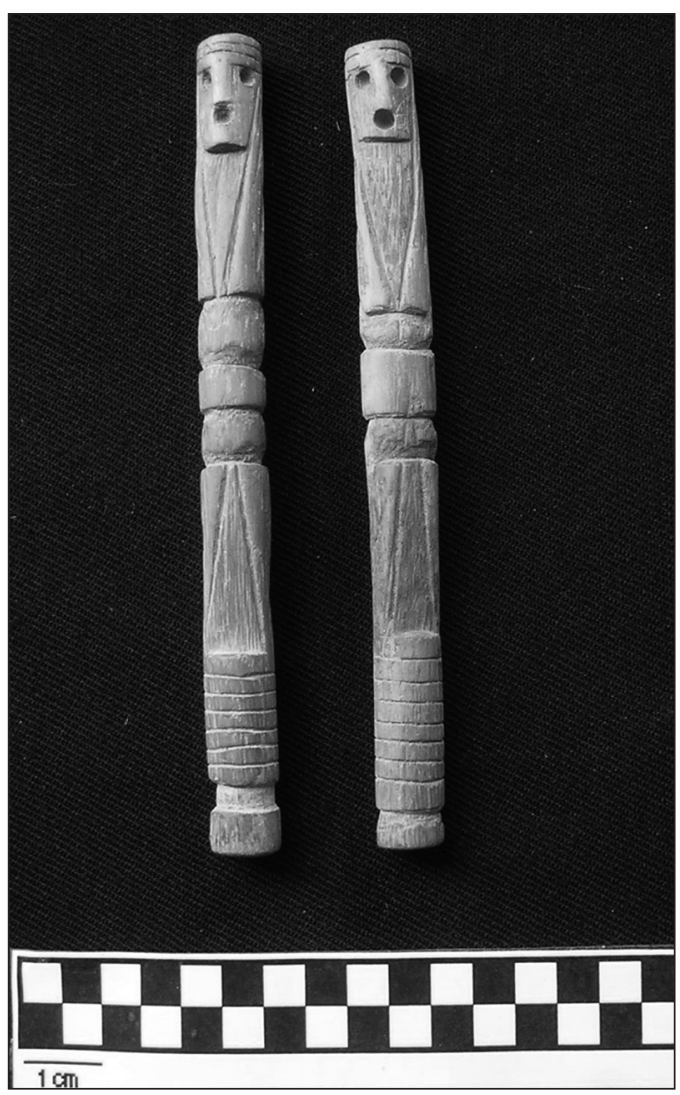

Figura 6. Colgantes antropomorfos de madera, Pircas.
Por otra parte, la piezas semidiscoidales fueron elaboradas en madera muy liviana -en rigor una constituye un cuarto de disco y la otra un tercio del mismo- y como en el caso anterior, se recuperaron de los recintos 198 y 251. Ambas piezas son también muy estandarizadas, con diámetros (proyectados) de $8.5 \mathrm{~cm}$ y $2.4 \mathrm{~cm}$ de espesor. Ambos presentan una perforación muy fina hecha con aguja, lo cual es posible considerando que se trata de una madera blanda. En base a ello, proponemos que estos artefactos podrían constituir flotadores de pesca, lo cual deberá confirmarse en el futuro a partir de su comparación con artefactos similares de los contextos del litoral (Figura 7).

Por su parte, el madero perciforme posee un tamaño de 5 $\mathrm{x} 16 \mathrm{~cm}$ y un espesor de $0.3 \mathrm{~cm}$ y se halló en el entierro del recinto 198 de Pircas. La pieza presenta una perforación en lo que sería el ojo del pez y se encuentra fracturada en lo que correspondería a la cola. Llama la atención, además, que la madera escogida presenta dos vetas que otor-

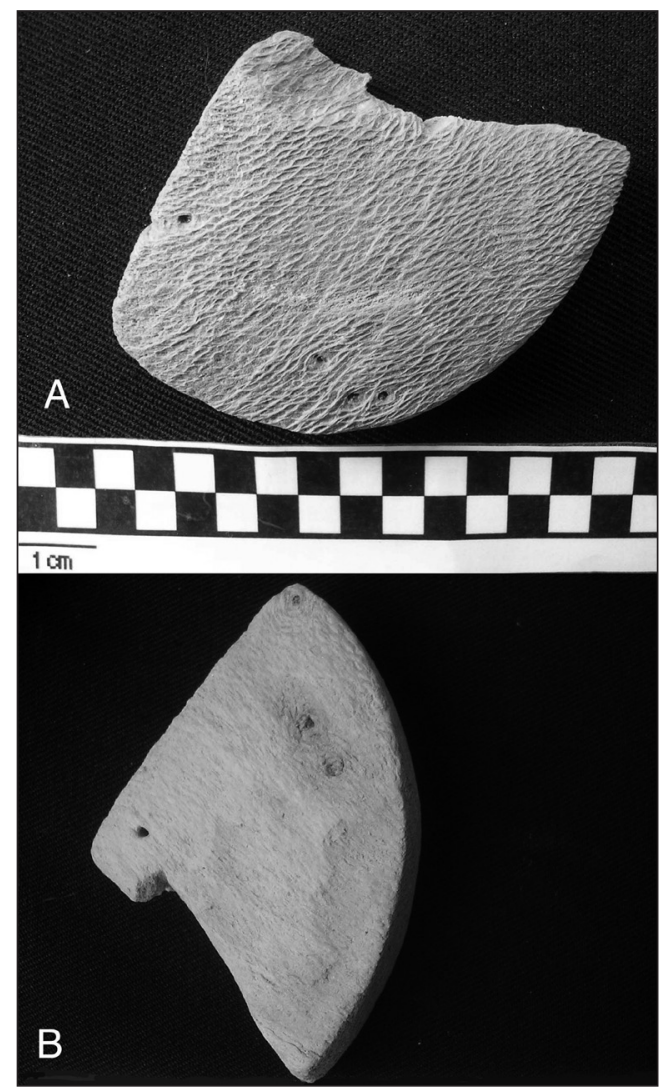

Figura 7. Posibles flotadores de pesca tallados en madera, Pircas.

No $47 / 2014$
ESTUDios ATACAMEÑos
Arqueología y Antropología Surandinas 
gan tonos café diferenciados para el dorso y el vientre, constituyendo un eje axial de simetría (Figura 8). Destacamos, por último, la preforma de tableta proveniente del mismo contexto, la cual debió fracturarse al rebajar el recipiente. Posee un largo total de $17.6 \mathrm{~cm}$ y $9.6 \mathrm{~cm}$ de ancho, mientras que el recipiente tiene una dimensión de 7 $\times 3 \mathrm{~cm}$. En ella es posible visualizar las huellas de desbaste tanto en la cara anterior como posterior $y$, en este sentido, el ancho de la gubia con la cual fue tallada fue de 0.5 $\mathrm{cm}$. Si bien aparenta constituir una tableta para depositar sustancias psicoactivas o medicinales, sus dimensiones no nos permiten descartar que se trate de una tablilla "portaplumas", anteriormente registradas en Azapa 71 (Formativo), Pica 8 (Intermedio Tardío) y en Quillagua (Horta 2010). De todos modos, ambos tipos de tabletas han sido vinculadas al complejo alucinógeno (Ayala et al. 1999) y, en este sentido, podemos asociarla con otros hallazgos, como la semilla de cebil (Anadenanthera colubrina) recuperada en el recinto 7 de Caserones (Figura 9) así como las evidencias del sitio Tr-40, donde se halló un

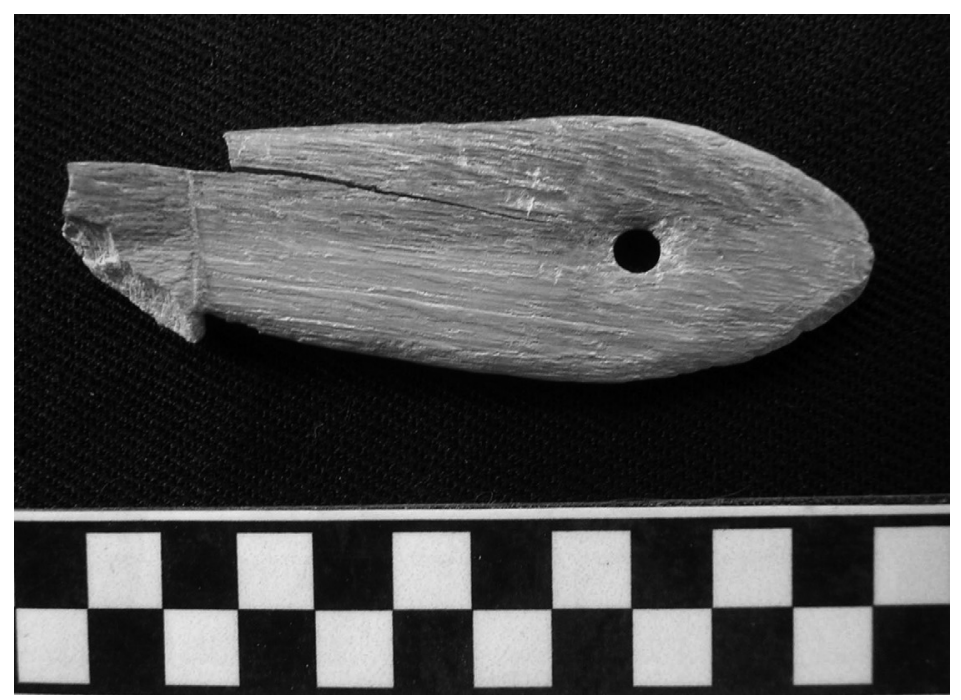

Figura 8. Madera tallada con forma de pez, Pircas.

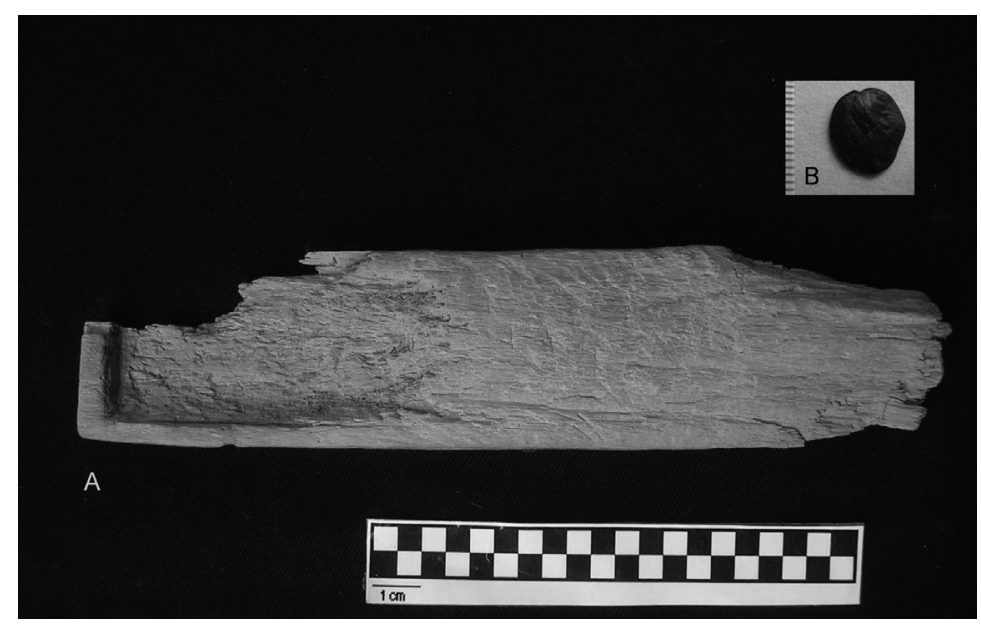

Figura 9. Preforma de tableta, Pircas. 
conjunto de semillas de esta especie (Méndez-Quirós et al. $2009 \mathrm{Ms}$ ) así como los tubos y espátulas ya mencionados. Considerando toda la documentación disponible, completan la parafernalia psicotrópica de la región de Tarapacá los hallazgos realizados en los cementerios costeros de Bajo Molle y Patillos, correspondientes a cuatro tubos, una boquilla de hueso y dos tabletas, una de ellas con el motivo del "sacrificador" (Moragas 1995), así como las semillas de cebil descritas para los cementerios formativos de Quillagua 84 y 89 (Agüero y Uribe 2013).

Por último, del análisis de la anatomía de las maderas de los instrumentos de Caserones se ha determinado que dos de ellos fueron hechos de molle (Schinus molle), un tercero corresponde a Prosopis sp., probablemente Prosopis algarrobilla, mientras que un cuarto instrumento no pudo vincularse con ninguna de las maderas de la colección de referencia.

\section{Desechos de talla en madera}

Los desechos de talla en madera o virutas corresponden a desechos potencialmente derivados tanto de los artefactos formatizados como de los expeditivos ya mencionados. En total se analizaron 358 virutas en Caserones, 51 en Pircas y 16 en Guatacondo. Entre ellas se registra un astillamiento secundario predominante, bordeando el 70\% en las aldeas de Tarapacá y 95\% en Guatacondo (Tabla 4). De este modo, la disminuida presencia de astillamiento primario, junto con el predominio de virutas de tamaños pequeños, que promedian entre 2 a $4 \mathrm{~cm}$ de largo, permite argumentar que las primeras fases de las cadenas productivas, incluyendo limpieza y reducción de materias primas, se estarían realizando en los bosques,

\begin{tabular}{|l|c|c|c|c|c|c|}
\hline \multirow{2}{*}{ Sitios } & \multicolumn{2}{c|}{$\begin{array}{c}\text { Virutas } \\
\text { primarias }\end{array}$} & \multicolumn{2}{c|}{$\begin{array}{c}\text { Virutas } \\
\text { secundarias }\end{array}$} & \multicolumn{2}{c|}{ Total } \\
\cline { 2 - 7 } & N & $\%$ & N & $\%$ & N & $\%$ \\
\hline Pircas & 12 & 23.53 & 39 & 76.47 & 51 & 100 \\
\hline Caserones & 73 & 20.39 & 285 & 79.61 & 358 & 100 \\
\hline Guatacondo & 1 & 6.25 & 15 & 93.75 & 16 & 100 \\
\hline Total & 86 & 20.24 & 339 & 79.76 & 425 & 100 \\
\hline
\end{tabular}

Tabla 4. Distribución y frecuencia de desechos de talla en madera o virutas. desde donde éstas se transportarían en forma de núcleos de madera a los recintos habitacionales. Allí se desarrollarían posteriormente las etapas finales de reducción, limpieza y/o cepillado de los artefactos, relacionados con su terminación o retoque. El modelo anterior se justifica, además, por la cercanía de las aldeas a las fuentes de aprovisionamiento, con lo cual resulta innecesario transportar grandes volúmenes de materia prima a las aldeas (García et al. 2009).

\section{Artefactos en fibra vegetal}

Los artefactos elaborados en fibra vegetal suman 53 unidades, todos ellos distribuidos homogéneamente entre las aldeas de Pircas $(\mathrm{N}=28)$ y Caserones $(\mathrm{N}=24)$, sumando a un único ejemplar en Guatacondo. Dichos artefactos corresponden a 43 fragmentos de cordelería, tres cañas aguzadas, dos cañas cortadas, dos ovillos, dos palos embarrilados y una estera. La observación macroscópica y su comparación con ejemplares de referencia nos permite señalar que las fibras utilizadas para estos fines corresponden, entre otros, a tallos de poáceas o gramíneas, entre ellas maíz (Zea mays), junto con cañaveral (Phragmites australis), junquillo (Scirpus sp.), totora (Typha angustifolia) y algodón (Gossypium sp.).

En relación a la cordelería, se observaron tallos con torsión simple y doble en $\mathrm{S}$ o $\mathrm{Z}$ indistintamente. Además, en el recinto 251 de Pircas la mayor parte de la cordelería está referida a fragmentos de trenzas muy densas similares a los que envuelven los fardos funerarios de Tr-40, interpretados como zunchos para transportar las momias. A este contexto se asocia, además, el único fragmento de estera de totora (Typha sp.) muy mal conservado y un pequeño conglomerado similar a un ovillo muy denso de $4 \mathrm{~cm}$ de diámetro donde se observan tallos sin torsión, de diferentes grosores. En el recinto 198, asociado a la tumba, está presente una caña con tres perforaciones que pudo constituir una flauta, la cual luego de aplastada fue embarrilada con lana y cuero. En el recinto 314 de Caserones destaca una hermosa pieza elaborada con las glumas u hojas que cubren la mazorca aún adheridas a la base, las cuales fueron torcidas en Z (Figura 10).

El aprovisionamiento de las fibras vegetales es netamente local y debió formar parte de las tareas habituales de recolección. Ello se encuentra atestiguado en la gran 
cantidad de tallos de estas mismas especies que no presentan intervención (ecofactos), los cuales pueden ser considerados como materias primas dentro de las cadenas productivas de estos artefactos. Una vez transportada la materia prima a los recintos se llevarían a cabo las tareas de limpieza, para su posterior manufactura previa al secado. En el caso específico del algodón, junto a los pequeños fragmentos hilados, en Caserones encontramos 21 semillas y un trozo de mota, similar al hallado en Pircas donde, además, se recuperaron cinco semillas en los dos recintos ya mencionados. La presencia de semi- llas de esta última especie también debe vincularse con los procesos de limpieza de las fibras previo al hilado.

\section{Artefactos en espina de cactus}

La cadena operativa de los artefactos elaborados en espinas de cactáceas ha sido reconstruida fundamentalmente a partir del material de Pircas, donde se hallaron dos espinas sin modificación, tres preformas de agujas y cinco artefactos terminados, usados y acabados, también provenientes de los recintos 251 y 198. Las dos espinas sin

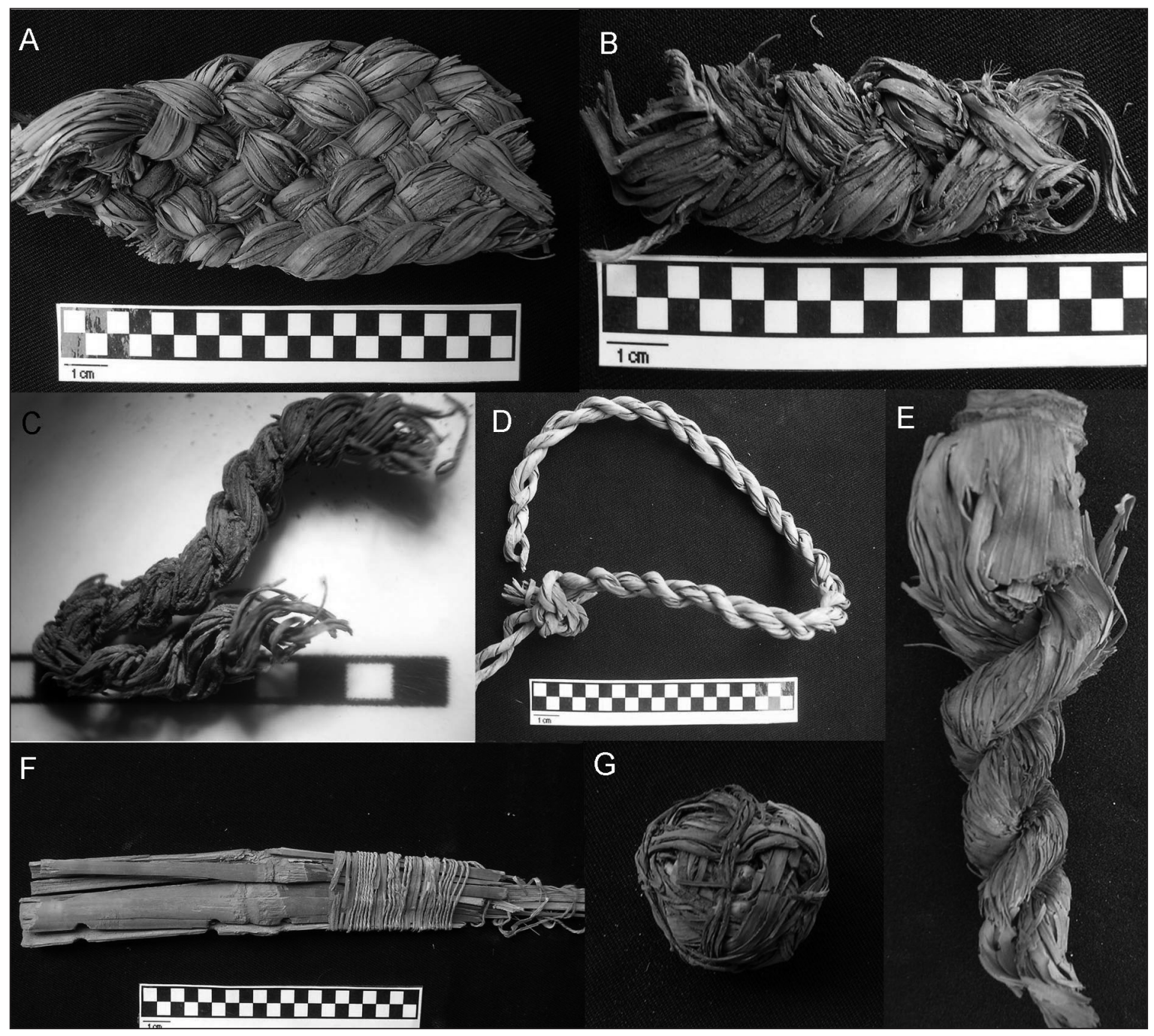

Figura 10. Artefactos elaborados en fibras vegetales: a) Zuncho, Pircas; b) Trenza, Pircas; c) Cordelería, Guatacondo 1; d) Cordelería, Pircas; e) Hojas de maíz torcidas, Caserones; f) Caña (Phragmites sp.) perforada aplastada y posteriormente embarrilada (posible flauta),

Pircas; g) Ovillo de diferentes fibras sin torsión, Pircas. 
modificaciones pueden ser consideradas como evidencias de materia prima. Si bien no hemos realizado análisis específicos para precisar su adscripción taxonómica, nos aventuramos a proponer que se trataría del ya mencionado cactus copao (Eulychnia iquiquensis). Cualquiera sea el caso, notamos una selección enfocada a espinas que superan los $7 \mathrm{~cm}$ de largo, con un diámetro que bordea los 0.3 cm en su parte más ancha.

Una vez recolectadas en las serranías costeras, su proceso de transformación comienza con el tratamiento térmico de la espina, que permite otorgarle rectitud y resistencia a la pieza. Ello se evidenció en dos ejemplares arqueológicos a partir de manchas más oscuras (ambas del recinto 251). Luego, otras preformas documentan una segunda etapa referida al proceso de pulido completo de la pieza, lo que debió facilitar el deslizamiento de la aguja por las fibras. En complemento, un ejemplar manifiesta que el extremo de la perforación es previamente aplanado, con lo cual se evitaría la fractura al momento de la perforación, pues entrega una mayor superficie de apoyo alivianando la presión ejercida por el perforador. Por último, destaca un ejemplar inédito con perforaciones en ambos extremos, del cual desconocemos hasta el momento su forma de uso (Figura 11).

Si bien consideramos que la industria de espinas de cactácea en Pircas se orientaría más que nada a la elaboración de agujas, que a su vez tienen una expresión indirecta aunque elocuente en las miniaturas de Tr-40 y en la técnica de anillado típica del Formativo (Agüero 2012), no podemos descartar otros usos como alfileres, buriles para pirograbar calabazas $y / o$ limpiadores de tubos, como se evidencia en Tr-40 donde al interior del tubo mencionado se registró un atado de espinas (Catalán $2010 \mathrm{Ms}$ ).

\section{Artefactos elaborados en espinas de algarrobo}

A esta categoría corresponden cuatro espinas desbastadas y pulidas recuperadas de los recintos 7, 314 y 280 de Caserones. Estas piezas se caracterizan por estar desbastadas en el extremo opuesto a la punta, que plantea la posibilidad de que hayan sido enmangadas. Se identificaron como algarrobo (Prosopis sp.), en base a la comparación con las espinas de la misma especie presentes en el sitio (ecofactos), así como de ejemplares actuales de referen- cia. Si bien desconocemos su funcionalidad, formalmente se asemejan a buriles.

\section{Artefactos elaborados en semillas}

A esta categoría se asocia una cuenta discoidal elaborada en una semilla de color negro y textura brillante, de 0.5 $\mathrm{cm}$ de diámetro. Se trata de una especie foránea, probablemente de los valles cálidos de la vertiente oriental andina. Se asemeja a las cuentas registradas en Playa Miller 7 y Azapa 71, identificadas erróneamente como Mucuna elliptica (Erices 1975; Santoro 1980), aunque estas últimas son más pequeñas y, en este sentido, se trataría de otra especie. Otras cuentas elaboradas en semillas similares son mencionadas para los sitios formativos de Quillagua 84 y 89 (Agüero y Uribe 2013).

\section{Calabaza usada como contenedor}

Si bien es posible que los pericarpios de calabaza (Lagenaria siceraria) mencionados como desechos de alimentos hayan podido servir de contenedores, asignamos a esta categoría únicamente los fragmentos de pericarpio que mostraron algún grado de intervención antrópica y que en la muestra total solo hay un fragmento. Éste, hallado en el recinto 516 de Caserones, corresponde a un borde, en cuyo interior se preservan restos de pigmento rojo.

\section{* Los vegetales en la conformación de las SOCIEDADES FORMATIVAS TARAPAQUEÑAS}

Como hemos visto, los restos vegetales recuperados de las aldeas formativas de Tarapacá documentan dimensiones básicas de la vida social, principalmente alimentación, artesanía y construcción. Por una parte, la diversidad de alimentos presentes fue relevada en tres tipos de espacios, que incluyen contextos de preparación y consumo, pozos de almacenaje y contextos ceremoniales. Estos corresponden a frutos recolectados en los bosques y quebradas, así como productos obtenidos de los campos agrícolas, identificados como molle (Schinus molle), algarrobo (Prosopis sp.), chañar (Geoffroea decorticans), maíz (Zea mays), calabaza (Lagenaria siceraria), poroto (Phaseolus vulgaris), pallar (Phaseolus lunatus), quinoa (Chenopodium quinoa) y amaranto (Amaranthus sp.). Estas 


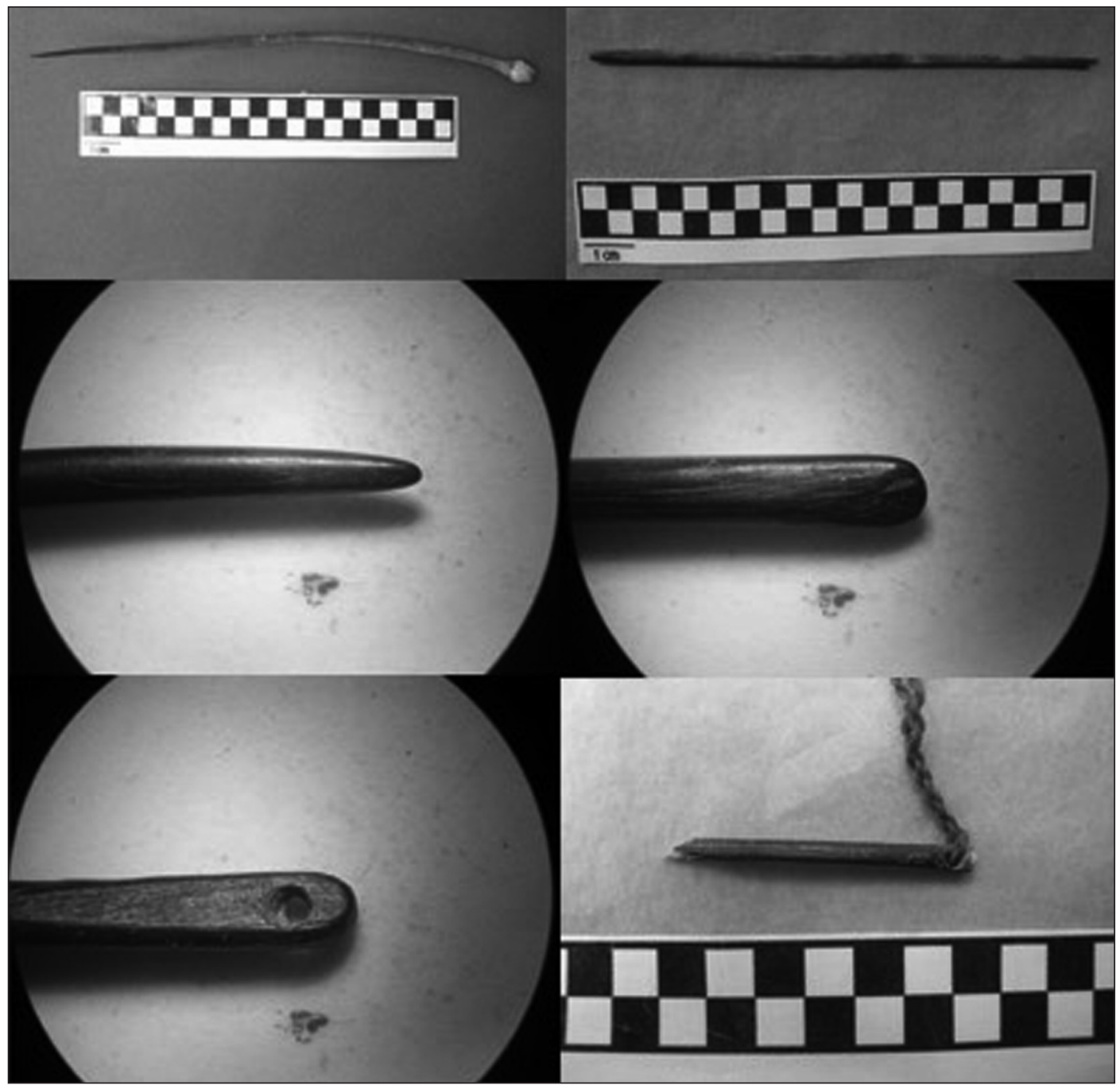

Figura 11. Etapas de la cadena de elaboración de agujas de espinas de cactus, Pircas.

últimas evidencias conformarían, hasta el momento, los contextos agrícolas más tempranos de la Pampa del Tamarugal, especialmente los cultivos fechados en la aldea Guatacondo (quinoa, calabaza y maíz) entre 160 AC y $70 \mathrm{DC}$.

Si bien falta mucho por hacer en términos cronológicos y genéticos, estos cultivos debieron ingresar a la región ya domesticados, lo cual no implica que no haya existido un proceso de experimentación local para adecuar dichas especies a los suelos locales. Asimismo, y como planteamos al comienzo, es necesario superar las visiones dicotómicas, en este caso el dualismo salvaje/domes- ticado, que necesariamente obstaculiza la clasificación de ciertos ejemplares cultivados que derivan de grados muy disímiles de asociación con el humano. Siguiendo a Lema (2009), hay una ausencia de criterios apropiados para referirse a los cultivos que se ubican en etapas intermedias de domesticación, problema que en nuestra área de estudio vinculamos principalmente al algodón y a las chenopodiáceas, ya que constituyen taxas muy difíciles de clasificar en una u otra categoría.

Complementariamente, la presencia de pozos de almacenaje distribuidos al interior de las viviendas confirma la capacidad excedentaria de estas comunidades, la 
cual se irá acrecentando a lo largo del primer milenio de nuestra era, como se observa en Caserones. Esta práctica la vinculamos con una alta productividad agrícola y una recolección intensiva de algarrobo, favorecida por mejores condiciones de humedad en el ambiente, aunque más que nada por una cohesión social acentuada, manifestada en la organización del trabajo. Dicha organización se expresa principalmente en la desafiante tarea de irrigar el desierto, pero también en los grandes espacios de congregación que se construyeron al interior de las aldeas (Urbina et al. 2012). Al mismo tiempo, los excedentes reunidos en forma de comida y bebida debieron orientarse a nutrir esta cohesión social, así como a surtir a la unidad doméstica durante el ciclo anual. Igualmente, no podemos descartar que estos mismos recursos hayan motivado relaciones con otras comunidades, principalmente con la costa de Iquique, Bajo Molle y los Verdes, desde donde debieron provenir los productos marinos presentes en Pircas, Caserones y Tr-40. Al mismo tiempo, todos los sitios comparten elementos específicos, tales como tecnologías en fibras vegetales, lienzas de algodón y agujas en espinas de cactus, entre otros (Moragas 1995).

En la aldea de Guatacondo, por su parte, si bien los productos marinos están presentes, la presencia del cactus tunilla (Opuntia sp.) apoya los vínculos con las tierras altas, sugeridos anteriormente en base a la similitud del patrón arquitectónico de esta aldea con la aldea Tulor, en San Pedro de Atacama, y en base a la lámina de oro con el motivo del personaje frontal radiado hallada en el cementerio Guatacondo 12 similar a la lámina de Tulan (Mostny 1971; Meighan 1980; Núñez y Santoro 2011).

Junto con ello, se registraron especies provenientes de las yungas orientales, específicamente una semilla de cebil (Anadenanthera colubrina) y cáscaras de maní (Arachis hypogaea). Además, hallamos una cuenta de collar elaborada en una semilla de apariencia subtropical o tropical de proveniencia indeterminada. Si bien tradicionalmente estos elementos se vinculan con un uso ceremonial o restringido, fueron recuperados de las basuras domésticas de Caserones, lo que denota una manipulación cotidiana de los mismos.

En otro ámbito, salvo tres ejemplares, todos los artefactos analizados provienen de las aldeas de la quebrada de
Tarapacá. De diversas maneras, las distintas categorías de artefactos evocan nuevamente los nexos con la costa. Como en los sitios costeros, las fibras vegetales se manifiestan principalmente en fragmentos de cordelería de manufactura variada, y en menor medida cañas aguzadas o cortadas así como ovillos y fragmentos de esteras. Por su parte, entre los artefactos elaborados en espinas, distinguimos en Caserones pequeños instrumentos similares a buriles elaborados en espinas de algarrobo (Prosopis sp.), así como agujas de espina afines a las del cactus copao (Eulychnia iquiquensis). Estas últimas aparecen representadas en sus diferentes fases de la cadena productiva, que junto con documentar sus formas de elaboración, evidencian su empleo cotidiano que vinculamos a la manufactura de las decenas de miniaturas de cestos y textiles presentes en $\operatorname{Tr}-40$, así como a las bolsas y gorros tejidos con técnica de anillado típicamente formativo (Agüero 2012). Como hemos mencionado, estas agujas también forman parte de los contextos costeros, lo cual refuerza la idea que se trate del cactus copao, cuyo hábitat natural se circunscribe a la cordillera de la Costa por donde cruzan los senderos que comunican ambos espacios (Núñez 1976, 1985; Briones et al. 2005; Pinto 2007).

Complementariamente, la producción local de artefactos en madera se encuentra atestiguada por más de 400 desechos de talla, principalmente vinculados al astillamiento secundario, lo cual sugiere que las primeras etapas del proceso productivo se estarían realizando fuera de las aldeas, probablemente en los mismos bosques. $\mathrm{Al}$ mismo tiempo, hemos documentado 20 artefactos con muy disímil escala de formatización. Por una parte, son frecuentes los soportes intervenidos de forma expeditiva que alcanzan el $45 \%$ del total (p.e., palos aguzados, cortados, incisos y embarrilados). El 55\% restante es de mayor formatización, y hasta el momento solo había sido registrado en contextos funerarios. Entre estos últimos, nos interesa destacar los artefactos tallados en madera de Pircas, específicamente los cinco colgantes estandarizados que presentan un rostro frontal, la preforma de tableta, la madera tallada con forma de pez y las piezas semidiscoidales elaboradas en madera liviana que interpretamos como flotadores de pesca. En relación a la preforma de tableta, ésta evidencia una producción local, lo cual es significativo considerando la presencia restringida que posee el complejo alucinógeno 
en la región tarapaqueña. Por todo lo anterior, se podría proponer que los imaginarios a los que aluden los artefactos de madera incluyen de manera significativa el tema del mary, en este sentido, en dichas piezas se integran simbólicamente los espacios forestales y costeros.

Finalmente, hemos podido constatar que junto con las semejanzas que manifiestan las cuatro aldeas, relacionadas fundamentalmente con su orientación agrícola y forestal, ambas cuencas muestran expresiones diferentes de lo que sería el período Formativo en Tarapacá. Por una parte, las aldeas Pircas y Caserones se vinculan a una ocupación continua en el tiempo muy ligada a la explotación de los bosques y la interacción con la costa, entre las cuales la primera es tres siglos más temprana que la segunda y presenta una ocupación mucho más extensiva. En concordancia con ello, constatamos el despliegue de diversas actividades realizadas de manera intensiva y sucesiva en el tiempo, ligadas, entre otras, a una alta producción y consumo de alimentos, recolección intensiva de vainas de algarrobo, manufactura especializada de artefactos en madera y fibras vegetales que evocan actividades diversas. Mientras que, por su parte, las ocupaciones de las aldeas Guatacondo y Ramaditas son contemporáneas y más acotadas, extendiéndose entre 370 AC y 70 DC. Se trata, en ambos casos, de una sola ocupación que se inicia con fechas contemporáneas a la ocupación de Pircas, aunque sin superposiciones posteriores como se observaron en esta última. Asimismo, estos depósitos más acotados evidencian actividades visiblemente más restringidas en relación a las aldeas de la quebrada de Tarapacá, principalmente ligadas a la producción, consumo y almacenaje de alimentos. En ellas, además, están ausentes la amplia gama de artefactos registrados en las primeras aldeas, reforzando la idea de una reducción de actividades.

Lo anterior parece reflejar una situación mucho más experimental para las aldeas de Guatacondo, donde, además, no existe asociación a cursos de agua permanente como ofrecen las vertientes de Huarasiña, que hasta la actualidad riegan los campos adyacentes a las aldeas de la quebrada de Tarapacá. Así, mientras que las aldeas de
Tarapacá fueron habitadas de forma permanente durante todo el año y, en este sentido, constituyeron espacios de reproducción social en todas sus dimensiones, en las aldeas de Guatacondo planteamos la posibilidad de que su ocupación haya sido estacional con un objetivo mucho más focalizado en función de la producción agrícola, la cual solo fue posible en los meses de verano con la activación del río producto de las lluvias altiplánicas. Tomando en cuenta los resultados obtenidos desde la dendrocronología y los antecedentes polínicos, estas lluvias habrían sido más abundantes que en la actualidad, lo cual junto con favorecer la cobertura vegetacional de las especies nativas podría explicar las enormes extensiones de campos cultivados aledaños a las aldeas en cuestión, los cuales difícilmente podrían ser regados con la disponibilidad de agua actual. En el caso de la quebrada de Guatacondo, los productos agrícolas que analizamos nosotros y otros investigadores, darían cuenta que el incentivo más importante para llevar a cabo esta trashumancia se vincularía con el cultivo de quinoa. Por último, considerando la mayor vulnerabilidad del ambiente donde se emplazan estas últimas aldeas, es posible pensar que a comienzos de nuestra era, continuar arribando cada verano a irrigar estas extensiones de desierto pudo tener un costo muy alto, que finalmente pudo motivar su abandono.

Agradecimientos Los autores agradecen a los proyectos FONDECYT 1080458 y 1130279 , especialmente a su investigador responsable Mauricio Uribe, así como al resto del equipo: Leonor Adán, Carolina Agüero, Rolando Ajata, Gloria Cabello, Danisa Catalán, Josefina González, Pablo Méndez-Quirós, Constanza Pellegrino, Rodrigo Retamal, Simón Urbina, Jimena Valenzuela y Estefanía Vidal. Asimismo, expresamos nuestra gratitud a Gloria Palape y Félix Aimani de la comunidad de Guatacondo, y a Eduardo Relos de la comunidad de Huarasiña por hospedarnos y apoyar con sus conocimientos esta investigación. A Mónica Rayo por colaborar en la identificación de instrumentos de madera de Caserones. A Charles Rees y Claudia Amuedo por la revisión de los borradores y, finalmente, a los evaluadores anónimos que permitieron mejorar este artículo. 


\section{* Referencias citadas}

AGÜERO, C., 2012. Textiles del asentamiento Caserones y su cementerio: Significado social y político para la población tarapaqueña durante el período Formativo (norte de Chile). Revista Chilena de Antropología 26:59-94.

AGÜERO, C. y M. URIBE, 2013. Tombs and tumuli on the coast and pampa of Tarapacá: Explaining the Formative period in Northern Chile (South-Central Andes). En Funerary practices and models in the Ancient Andes, P. Eeckhout y L. Owens (Eds.). Cambridge University Press, Cambridge. En prensa.

AYALA, P., O. REYES y M. URIBE, 1999. El cementerio de los abuelos de Caspana: El espacio mortuorio local durante el dominio del Tawantinsuyu. Estudios Atacameños 18: 35-54.

BAIERD, A. y E. ROSELLÓ, 2005. A new proxy for late Holocene landscape change at Quebrada Tarapacá, Chile. Poster. $2^{\circ}$ Southern Desert Conference. Human-Environment Interactions in Southern Hemisphere Deserts: Past, Present, and Future. Arica.

BERMÚdEZ, O., 1963. Historia del salitre. Desde sus orígenes hasta la guerra del Pacífico. Ediciones de la Universidad de Chile, Santiago.

BRIONES, L., 1985. Visión retrospectiva antropológica del Prosopis. Estado actual del conocimiento sobre Prosopis tamarugo. Universidad de Tarapacá, Corporación Nacional Forestal, Arica.

BRIONES, L., L. NÚÑEZ y V. STANDEN, 2005. Geoglifos y tráfico prehispánico de caravanas de llamas en el desierto de Atacama (norte de Chile). Chungara 37 (2): 195-223.

COOK, E., K. BRIFFA, S. SHIYATOV y V. MAZEPA, 1990. Treering standardization and growth-trend estimation. En Methods of dendrochronology, E. Cook y L. Kairiukstis (Eds.), pp. 104-132. Kluwer Academic, Dordrecht.

COUYOUMDJIAN, R. y H. LARRAÍN, 1975. El plano de la quebrada de Tarapacá, de don Antonio O'Brien. Su valor geográfico y socio-antropológico. Norte Grande 1 (3-4):330-357.

CASTRO, L., 2004. Recursos hídricos altoandinos, estrategias de desarrollo económico y proyectos de riego: Tarapacá, 18801930. Chungara, Revista de Antropología Chilena 36 (1): 205-220.

CASTRO, V. y M. ROMO, 2006. Tradiciones culturales y biodiversidad. En Biodiversidad y recursos. Patrimonio y desafio. Comisión Nacional de Medio Ambiente (CONAMA), Santiago.

CATALÁN, D., 2010 Ms. De miniaturas y otros objetos: Re-conociendo la colección del cementerio Tarapacá 40, norte de Chile (período Formativo). Informe proyecto FONDECYT 1080458, Santiago.

ERICES, S., 1975. Evidencias de vegetales en tres cementerios prehispánicos, Arica-Chile. Chungara 5 (1): 65-71.

FRITTS, H., 1976. Tree rings and climate. Academic Press, Londres.

GARCÍA, M., A. VIDAL, R. CORDERO y E. BELMONTE, 2009. Las industrias madereras vinculada a sitios habitacionales de Tarapacá. Actas del al ХVIII Congreso Nacional de Arqueología Chilena, Valparaíso. En prensa.

GARCÍA, M., A. MALDONADO, A. VIDAL, M. P. PEÑA, S. URBINA, L. ADÁN y M. URIBE, 2011. Arqueobotánica y dendrocronología durante el período Formativo (2500-1100 años AP) en la región de Tarapacá, Chile. Poster. IV Congreso Internacional de Ecosistemas Secos, Arequipa.

GAYÓ, E., C. LATORRE, C. SANTORO, A. MALDONADO y R. DE POL-HOLZ, 2012. Hydroclimate variability in the lowelevation Atacama Desert over the last 2500 yr. Climate of the Past 8: $287-306$.

HERRERA, M. J., 2010. Caracterización de los modos de vida y análisis de salud y dieta a través de las piezas óseas y dentales en esqueletos del cementerio Caserones-Tarapacá 40 (período Formativo, región de Tarapacá). Informe de Práctica Profesional, Departamento de Antropología, Universidad de Chile, Santiago.

HIDALGO, J., 2009. Civilización y fomento: La "Descripción de Tarapacá” de Antonio O'Brien, 1765. Chungara, Revista de Antropología Chilena 41 (1): 5-44.

HORTA, H., 2010. El señorío Arica y los reinos altiplánicos: Complementariedad ecológica y multietnicidad durante los siglos pre-conquista en el norte de Chile (1000-1540 DC). Tesis Doctoral. Departamento de Ciencias Históricas, Universidad de Chile, Santiago.

HOFFMANN, A., 1989. Cactáceas en la flora silvestre de Chile. Fundación Claudio Gay, Santiago.

HOUSTON, J., 2002. Groundwater recharge through an alluvial fan in the Atacama Desert, northern Chile: Mechanisms, magnitudes and causes. Hydrological Processes 16 (15): 3019-3035.

INGOLD, T., 2000. The perception of environment. Essays on livelihood, dwelling and skill. Routledge, Londres y Nueva York. 
JAMES, L., 1980. An analysis of cultivated plant remains from Guatacondo, Chile. En Prehistory trails of Atacama: Archaeology of northern Chile. Monumenta Archaeologica 7, C. Meighan y D. True (Eds.), pp. 127-133. The Institute of Archaeology, University of California, Los Angeles.

KAUTZ, R., 1980. Palynology of coprolites from sites in northern Chile. En Prehistory trails of Atacama: Archaeology of northern Chile. Monumenta Archaeologica 7, C. Meighan y D. True (Eds.), pp. 205-207. The Institute of Archaeology, University of California, Los Angeles.

LUMBRERAS, L., 2006. Un Formativo sin cerámica y cerámica preformativa. Estudios Atacameños, Arqueología y Antropología Surandinas 32: 11-34.

MALDONADO, A. y M. URIBE, 2011 Ms. Paleoambiente y complejidad social en Tarapacá, norte de Chile. Ponencia presentada en el IV Congreso Internacional de Ecosistemas Secos, Arequipa. Manuscrito en poder de los autores.

MALDONADO, A. y L. GONZÁLEZ, 2012 Ms. Análisis de polen fósil en paleomadrigeras de roedores, en la precordillera del salar del Huasco. Etapa II. Informe proyecto FONDECYT 1080458, Santiago.

MEIGHAN, C., 1980. Archaeology of Guatacondo, Chile. En Prehistoric trails of Atacama: Archaeology of northern Chile. Monumenta Archaeologica 7, C. Meighan y D. True (Eds.), pp. 99-126. The Institute of Archaeology, University of California, Los Angeles.

MÉNDEZ-QUIRÓS, P., 2012. Estratigrafía doméstica e historias ocupacionales en el período Formativo de la cuenca baja de la quebrada de Tarapacá. Memoria de Título en Arqueología, Departamento de Antropología, Universidad de Chile, Santiago.

MÉNDEZ-QUIRÓS, P., T. SÁNCHEZ y C. LEMP, 2009 Ms. Rescatando la prehistoria tarapaqueña. Conservación y puesta en valor de las colecciones arqueológicas de La Huayca, provincia del Tamarugal. Manuscrito en poder de los autores.

MORAGAS, C., 1995. Desarrollo de las comunidades prehispánicas del litoral Iquique-desembocadura río Loa. Hombre y Desierto 9 (1): 65-80.

MOSELEY, M., 1975. The maritime foundations of Andean civilization. Cummings Publishing Company, Menlo Park.

MOSTNY, G., 1971. La subárea arqueológica de Guatacondo. Boletín del Museo Nacional de Historia Natural tomo XXIX (16): 271-287.

MUÑOZ, I., 1982. Las sociedades costeras en el litoral de Arica durante el período Arcaico Tardío y sus vinculaciones con la costa peruana. Chungara 9: 124-151.
MUÑOZ, I., R. ROCHA y S. CHACÓN, 1991. Camarones 15. Asentamiento de pescadores correspondientes al Arcaico y al Formativo. Actas del XI Congreso de Arqueología Chilena, vol. 2, pp. 1-24. Santiago.

NIEMEYER, H., 1961. Excursiones a la sierra de Tarapacá. Arqueología, toponimia y botánica. Revista Universitaria XLVI: 97-114.

NOVOA, S., 2006. Sobre el origen de la tuna en el Perú. Algunos alcances. Zonas Áridas 10: 174-181.

NÚÑEZ, L., 1966. Caserones-I, una aldea prehispánica del norte de Chile. Estudios Arqueológicos 2: 25-29.

1969. El primer fechado radiocarbónico del Complejo Faldas del Morro en el sitio Tarapacá 40 y algunas discusiones básicas. Actas del VCongreso Nacional de Arqueología Chilena, pp. 47-58. La Serena.

1974. La agricultura prehistórica en los Andes Meridionales. Editorial Orbe, Santiago.

1976. Geoglifos y tráfico de caravanas en el desierto chileno. Homenaje al Dr. Gustavo Le Paige, s.j., J. M. Cassasas (Ed.), pp. 147201. Universidad del Norte, Antofagasta.

1979. Emergencia y desintegración de la sociedad tarapaqueña: Riqueza y pobreza de una quebrada del norte chileno. Atenea 439: 163-213.

1982. Temprana emergencia del sedentarismo en el desierto chileno: Proyecto Caserones. Chungara 9 (1): 80-122.

1984. El asentamiento Pircas: Nuevas evidencias de tempranas ocupaciones agrarias en el norte de Chile. Estudios Atacameños 7: 117-134.

1985. Petroglifos y tráfico en el desierto chileno. En Estudios en arte rupestre, C. Aldunate, J. Berenguer y V. Castro (Eds.), pp. 243-264. Museo Chileno Arte Precolombino, Santiago.

NÚÑEZ, L. y C. MORAGAS, 1977. Una ocupación con cerámica temprana en la secuencia del distrito de Cáñamo (costa desértica del norte de Chile). Estudios Atacameños 5 (1): 21- 49.

NÚÑEZ, L. y C. SANTORO, 2011. El tránsito Arcaico-Formativo en la Circumpuna y Valles Occidentales del Centro-Sur Andino: Hacia los cambios "neolíticos". Chungara, Revista de Antropología Chilena 43 (1): 487-530.

OAKLAND, A., 2000. Andean textiles from village and cemetery. Caserones in the Tarapaca valley, northern Chile. En Beyond cloth and cordage, archaeological textile research in the Americas, P. Drooker e I. Webster (Eds.), pp 229-251. The University of Utah Press, Salt Lake City. 
PARDO, O.yJ. L. PIZARRO, 2005. Especies botánicas consumidas por los chilenos prehispánicos. Colección Chile Precolombino, Editorial Mare Nostrum, Santiago.

PELLEGRINO, C., 2012. Arquitectura en el Formativo de Tarapacá: Análisis de diseño arquitectónico en Caserones y Guatacondo. Memoria de Título en Arqueología. Departamento de Antropología, Universidad de Chile, Santiago.

PINTO, R., 2007. Estado de conservación de Eulychnia iquiquensis (Schumann) Britton et Rose (Cactaceae) en el extremo norte de Chile. Gayana Botánica 64 (1): 97-108.

RIVERA, M., 1975. Una hipótesis sobre movimientos poblacionales altiplánicos y transaltiplánicos a las costas del norte de Chile. Chungara 5: 7-31.

1994. Hacia la complejidad social y política: El desarrollo Alto Ramírez del norte de Chile. Diálogo Andino 13: 9-37.

2002. Historias del desierto. Arqueología del norte de Chile. Editorial del Norte, La Serena.

RIVERA, M., D. SHEA, A. CAREVIC y G. GRAFFAM, 1995-96. En torno a los orígenes de las sociedades complejas andinas: Excavaciones en Ramaditas, una aldea formativa del desierto de Atacama, Chile. Diálogo Andino 14-15: 205-239.

SANTORO, C., 1980. Fase Azapa: Transición del Arcaico al desarrollo agrario inicial en los valles bajos de Arica. Chungara 6: 46-56.

SCHULMAN, E., 1956. Dendroclimatic changes in semiarid America. Laboratory of tree-ring research, University of Arizona. University of Arizona Press, Tucson.

SCHWEINGRUBER, F. H., 1988. Tree rings. Basics and applications of dendrochronology. Reidel Publ. Co., Dordrecht.

STALLER, J., 2006. La domesticación de paisajes. ¿Cuáles son los componentes primarios del Formativo? Estudios Atacameños, Arqueología y Antropología Surandinas 32: 43-57.

STANDEN, V., 2003. Bienes funerarios del cementerio Chinchorro Morro 1: Descripción, análisis e interpretación. Chungara 35: $175-207$.
TRUE, D., 1980. Archaeological investigations in northern Chile: Caserones. En Prehistoric trails of Atacama: Archaeology of northern Chile, C. Meighan y D. True (Eds.), pp. 139-178. Monumenta Archaeologica 7. The Institute of Archaeology, University of California, Los Angeles.

TRUE, D., L. NÚÑEZ, y P. NÚÑEZ, 1970. Archaeological investigations in northern Chile: Project Tarapacá. Preceramic resources. American Antiquity 35 (2): 170-184.

URBINA, S. y L. ADÁN, 2007. Construcciones de uso público y su distribución en las quebradas tarapaqueñas durante el período Intermedio Tardío (900-1450 DC). Boletín de la Sociedad Chilena de Arqueología 39: 19-34.

URBINA, S., L. ADÁN y C. PELLEGRINO, 2012. Arquitecturas formativas de las quebradas de Guatacondo y Tarapacá a través del proceso aldeano (ca. 900 AC-1000 DC). Boletín del Museo Chileno de Arte Precolombino 17 (1):31-60.

URIBE, M., 2008. El Formativo: ¿Progreso o tragedia social? Reflexiones sobre evolución y complejidad social desde Tarapacá (norte de Chile, Andes Centro-Sur). En Sed Non Satiata II, F. Acuto y A. Zarankin (Eds.), pp. 257-277. Encuentro Grupo Editor, Córdoba.

URIBE, M. y L. ADÁN, 2009. Evolución, Neolítico, Formativo y complejidad: Pensando el cambio desde Tarapacá (900 AC-800 DC). Actas del ХVIII Congreso Nacional de Arqueología Chilena, Valparaíso. En prensa.

VIDAL, A., 2010. Evaluación de la evidencia arqueobotánica durante el período Formativo en el Norte Grande de Chile. Werkén 12: 61-76.

VIDAL, E., 2009. Etnoarqueología de la fiesta andina: El caso de la región de Tarapacá. Informe de Práctica Profesional, Departamento de Antropología, Universidad de Chile.

VILLAGRÁN, C. y V. CASTRO, 2004. Ciencia indígena de los Andes del norte de Chile. Editorial Universitaria, Santiago.

VILLAGRÁN, C., V. CASTRO, G. SÁNCHEZ, F. HINOJOSA y C. LATORRE, 1999. La Tradición Altiplánica: Estudio etnobotánico en los Andes de Iquique, I Región, Chile. Chungara 31 (1): 81-186. 